\title{
Régimen jurídico de la Beneficencia y atención a los invidentes españoles en el siglo XIX
}

\author{
Juan Francisco Pérez Gálvez \\ Profesor Titular de Derecho Administrativo \\ Universidad de Almería
}

SUMARIO: 1. LA BENEFICENCIA Y LA SITUACIÓN DE LOS INVIDENTES. 1.1. CONCEPTO. 1.2. DIFERENCIA CON FIGURAS AFINES. 1.2.1. Caridad. 1.2.2. Filantropía. 1.2.3. Sociedades de asistencia, mutualidad o monte píos. 1.2.4. Hospicios y casas de misericordia. 1.2.5. Pobreza. 1.2.6. Miseria. 1.2.7. Indigencia. 1.3. La gestión de monopolios ocupacionales en manos de los invidentes. 1.4. Los establecimientos de beneficencia, las rifas y el recogimiento de los ciegos. 1.4.1. Evolución histórica de la beneficencia y la afectación de los establecimientos públicos. 1.4.2. La expresión "establecimiento público" en el derecho comparado. 1.4.3. La importación de la categoría de los "establecimientos públicos" en el derecho español. 1.4.4. Las rifas como medio de financiación de los establecimientos de beneficencia. 1.4.5. El recogimiento de los ciegos en establecimientos de beneficencia y su negativa a ingresar en asilos. 2. EDUCACIÓN: UNA HERRAMIENTA FUNDAMENTAL PARA EL AVANCE SOCIAL DE LOS INVIDENTES. 2.1. El paso de la prehistoria a la historia para los ciegos. 2.2. La creación de colegios para ciegos. 3. La primera organización legal de ciegos en España..

\section{LA BENEFICENCIA Y LA SITUACIÓN DE LOS INVIDENTES}

\subsection{Concepto}

Desde tiempos inmemoriales, la necesidad de atender a los más necesitados se hace patente. Ya en la Biblia encontramos referencias al mendigo Lázaro buscando las migajas del rico (Lucas, XVI, 19), el ciego de nacimiento curado por Jesús (Juan IX, 1) o el ciego Bartineo que mendigaba por los caminos de Jericó (Marcos, X, 46), y son sólo una breve alusión al mundo de la pobreza en el Nuevo Testamento. 
La palabra "beneficencia" se forma del adverbio latino bene, y del verbo facere, que juntos expresan la virtud y el acto de hacer el bien. Es de moderna introducción, tanto en la acepción general, como en la jurídica, pues en su lugar se empleaba antes la de caridad, en que predomina más el sentimiento cristiano, porque da a entender que el hacer bien a otro es un acto de amor a Dios y al prójimo. Desde que el socorro de la desgracia bajo sus diferentes aspectos, ha venido a formar un sistema completo, la expresión beneficencia es la que ha sustituido para señalar genéricamente la institución de la caridad general, y para designar con un solo nombre los establecimientos en que se ejerce con sujeción a las leyes y reglamentos ${ }^{1}$.

La beneficencia ${ }^{2}$ es aquel conjunto de prestaciones que, reconociendo normalmente como causa que la justifica una contraprestación compensadora, son dispensadas, no obstante, por un motivo de necesidad, de la realización efectiva de esa contraprestación ${ }^{3}$. El profesor F. Hernández Iglesias, la define así: «La beneficencia es el bien hecho por los funcionarios y por los pro-

${ }^{1}$ Vide J. ARIAS MIRANDA, Reseña histórica de la beneficencia española, Imprenta del Colegio de Sordomudos y de Ciegos, Madrid, 1862, pp. 75-164.

${ }^{2}$ Vide. Fernando GARRIDO FALLA, "La beneficencia general y particular. Situación y perspectivas", en AAVV, Problemas fundamentales de beneficencia y asistencia social, Ministerio de la Gobernación, Madrid, 1967, pp. 15-52; Ramón BADENES GASSET, Voz: "Beneficencia", Nueva En ciclopedia Jurídica, Tomo III, Barcelona, 1989.

${ }^{3}$ Vide Jaime GUASP, "La beneficencia como objeto formal de la actividad administrativa", Es tudios en homenaje a Jordana de Pozas, Instituto de Estudios Políticos, Madrid, 1962, p. 308. En la p. 315 afirma: «El resultado más importante que se obtiene de esta caracterización formal estriba, sin duda, en esa no identificación de lo benéfico con ningún campo material, concretamente acotado, de la acción del Estado o de los particulares. Diferenciación que no afecta sólo al contenido de la prestación, sino que afecta también a su continente, es decir, al modo de realizarse el favor que la prestación benéfica supone.

En efecto, es muy importante señalar ahora, porque en realidad constituye la idea central del presente trabajo, que la determinación formal de la beneficencia lleva a ésta a una posición autónoma e independiente y no confundible con ninguna otra, pero sólo desde el punto de vista de su perfil propio, en relación con otros servicios administrativos; es decir, que la ilimitación de la beneficencia no puede llevar en modo alguno al resultado de que ésta sea un mundo jurídico administrativo en miniatura, [...]. Todo lo contrario, la verdadera esencia de la beneficencia, por la identificación que postula entre los que tienen y los que no tienen, ha de llevar a organizarla en forma que a través de ella se consiga, pese a la diferencia formal de origen, una verdadera e inescindible equiparación de orden material». 
cedimientos administrativos, el conjunto de las instituciones encaminadas al socorro de los pobres, la síntesis de los auxilios sociales» 4 .

La Ley de Beneficencia de febrero de 1822, constituye un hito fundamental en lo que a política asistencial se refiere, tanto en cuanto, se trata del primer plan de organización de la beneficencia pública, centrando la atención a las necesidades en la Administración municipal, con la creación de las Juntas Municipales como resorte principal del sistema (art. 24) que actuaron como auxiliares de sus respectivos Ayuntamientos (art. 1).

Una de sus principales actuaciones fue el fomento de la asistencia domiciliaria, actuación que se mantendrá a lo largo de todo el siglo XIX.

Desde el punto de vista de la financiación, la novedad radicaba en la constitución de un fondo común que quedaba bajo la custodia de la autoridad municipal. De este modo quedaba la Iglesia en un segundo plano y se llegan a controlar incluso los fondos de la beneficencia privada: «Los fondos de beneficencia procedentes de fundaciones, memorias y obras pías de patronato público, sea Real o eclesiástico, cualquiera que fuese su origen primitivo, quedan reducidos a una sola y única clase, destinados al socorro de las necesidades que se provee por esta Ley» (art. 25).

La intervención de la administración no sólo se manifestaba en este aspecto, sino en la reconversión de establecimientos de beneficencia de carácter particular, en establecimientos públicos, mediante las correspondientes indemnizaciones a los patronos de los mismos.

El Real Decreto de 14 de marzo de 1899, art. 2, determina que son instituciones de beneficencia los establecimientos o asociaciones permanentes destinados a la satisfacción gratuita de necesidades intelectuales o físicas. Del mismo se desprenden las notas características de esta noción técnico-jurídica ${ }^{5}$ : - La beneficencia es, ante todo, una actividad que desarrollan determinadas instituciones (establecimientos o asociaciones). - Se requiere que dicha activi-

\footnotetext{
${ }^{4}$ Vide F. HERNÁNDEZ IGLESIAS, La beneficencia en España, Imprenta de Manuel Minesa de los Ríos, Madrid, 1879, pp. 11-282.

${ }^{5}$ Vide José Luís PIÑAR MAÑAS y Alicia REAL PÉREZ, Legislación sobre instituciones de beneficen cia particular, Ministerio de Trabajo y Seguridad Social, Madrid, 1987, pp. 19-20.
} 
dad sea permanente, quedando excluidas actuaciones ocasionales o esporádicas. - La finalidad perseguida por esa actividad ha de ser la satisfacción de necesidades (intelectuales o físicas), lo que implica que los destinatarios de la beneficencia son las personas necesitadas. Sin embargo no se otorga a las mismas derecho subjetivo alguno ${ }^{6}$. - La consecución de esta finalidad debe hacerse gratuitamente. - La beneficencia puede ser pública o particular.

\subsection{Diferencia con figuras afines}

\subsubsection{Caridad $^{7}$}

Corresponde sin duda al cristianismo el haber impulsado las bases espirituales del más decidido y espontáneo movimiento en pro de la ayuda a los necesitados $^{8}$. La caridad como amor de Dios participado por los hombres determinó desde los primeros siglos de su aparición la comunicación de bienes como acción eclesial realizada en nombre de la Iglesia entre los miembros de las comunidades cristianas. Las diconias primitivas suponían una auténtica repartición de recursos entre los cristianos de acuerdo con sus necesidades. Estas formas asistenciales evolucionaron a lo largo del tiempo, dando lugar a organizaciones más complicadas y con rasgos de cierta estabilidad. A lo largo de la Edad Media y hasta épocas bien recientes la Iglesia asumió sobre sí la tarea única de auxiliar a los indigentes, enfermos y necesitados en general. No obstante la caridad cristiana no tenía carácter social en el sentido de sociedad ar-

\footnotetext{
${ }^{6}$ Vide Manuel AZNAR LÓPEZ, "En torno a la beneficencia y su régimen jurídico", REDA, 92, (1996), pp. 558-559, donde explica, como a pesar de la gratuidad de la beneficencia: «[...]. Esta gratuidad no impedirá, sin embargo, que puedan ser atendidas, con carácter oneroso otras personas en los centros de beneficencia, lo que dará lugar a una asistencia discriminada. Así, el Reglamento de 1852 preveía, en los "establecimientos generales de locos", la existencia de "departamentos especiales para aquellos cuyas familias pudiesen costear sus estancias en los mismos" (art. 14) y permitía que los "establecimientos generales de ciegos y sordomudos" pudieran "recibir y educar a pacientes no pobres con la separación conveniente y por el estipendio que autoricen sus Reglamentos especiales" (art. 15)».

7 Vide: Paloma PERNIL ALARCÓN, "Caridad, educación y política ilustrada en el reinado de Carlos III”, Revista de Educación, Número especial, (1988), p. 332: caridad y reforma social en la España de Jovellanos; M. MOIX MARTÍNEZ, Bienestar social, Trivium, Madrid, 1986, p. 36 y ss.

${ }^{8}$ Vide Manuel AZNAR LÓPEZ, "En torno a la beneficencia y su régimen jurídico", REDA, 92, (1996), p. 555: «[...], la beneficencia ocuparía uno de los peldaños de la escala evolucionista, más concretamente el situado tras la caridad y antes de los ocupados por la asistencia social, la seguridad social y el bienestar social».
} 
ticulada, puesto que por sus propios fundamentos extraterrenos venía referida al hombre en cuanto imagen divina sobrepasando las comunidades organizadas. Pero con todo, como en tantos otros terrenos, la Iglesia vino a llenar también aquí eficazmente el vacío dejado en cuanto al atendimiento de necesidades públicas, por la ausencia de una organización administrativa adecuada $^{9}$.

Arias Miranda define este concepto de la siguiente manera: «Caridad: tiene esta palabra un sentido místico que expresa más en concreto el amor de Dios y el prójimo. Es aquella beneficencia expansiva, cordial, modesta, afectuosa, emanación genuina de la inspiración evangélica; constituida en una de las virtudes teologales, por cuanto tiene a Dios directamente por objeto de sus operaciones. Los hospicios y los hospitales tienen el nombre común de casas de caridad» ${ }^{10}$. Para Concepción Arenal, la caridad es la compasión cristiana que acude al menesteroso por amor de Dios y del prójimo ${ }^{11}$.

Debemos tener presente que el tránsito de la caridad a la beneficencia ${ }^{12}$ se produce por múltiples factores, y sobre todo resaltar que la beneficencia transfiere la obligación a la sociedad considerada como entidad colectiva, y por ello el término irá siempre seguido del apelativo pública.

\footnotetext{
${ }^{9}$ Vide Ramón MARTÍN MATEO, Guía de actividades públicas asistenciales. La asistencia social como servicio público, Ministerio de la Gobernación, Madrid, 1967, p. 18.

${ }^{10}$ Vide J. ARIAS MIRANDA, Reseña histórica de la beneficencia española, o.c., p. 75.

${ }^{11}$ Vide Concepción ARENAL, La beneficencia, la filantropia y la caridad, Imprenta Clásica Española, Madrid, 1927, p. 235.

12 Vide Luís JORDANA de POZAS, "Ideas fundamentales sobre la seguridad social”, Boletín de los Seminarios de Formación, Madrid, 1948, pp. 20-21: «[...]. Las instituciones asistenciales tienen una gloriosa progenie, son hijas exclusivamente del cristianismo, estaban inspiradas por la caridad, y se llamaban beneficencia. Consisten, por lo tanto, en hacer el bien. Y este nombre tan hermoso que responde también a su contenido y propósito, se vio un día que era antitético y se le quiso borrar sustituyéndolo con este otro término neutro que nada expresa, de la asistencia. Es que cuando la caridad y la beneficencia se convirtieron en asistencia, dejaron de inspirarse en el amor cristiano. Precisamente ese amor cristiano es la institución social por excelencia, la solución óptima como dijo nuestro Vives, para todos los problemas de carácter social. [...]». Vide Fernando GARRIDO FALLA, Tratado de Derecho Administrativo, Vol. II, Centro de Estudios Constitucionales, Madrid, 1980, pp. 334-336.
} 


\subsubsection{Filantropía ${ }^{13}$}

Filantropía es la compasión filosófica que auxilia al desdichado por amor a la humanidad y la conciencia de su dignidad y su derecho ${ }^{14}$.

El advenimiento del protestantismo produjo como reacción la sustitución de la idea de la caridad como motor de las acciones benevolentes, por la filantropía, la fraternidad y mutua ayuda, volviendo así en alguna manera a las tesis simplemente humanitarias sustentadas por los filósofos de la antigüedad.

La racionalización que empezó a experimentar la concepción de la vida a partir del Renacimiento motivó una corriente individualista, utilitarista y positivista, que sustituyó los impulsos caritativos por tendencias pragmatistas que buscaban la máxima efectividad de las ayudas y, sobre todo, el potenciar al máximo los propios recursos del individuo, al objeto de que, aprovechando sus propias posibilidades, fuese capaz de autosuperarse, dejando de constituir una carga para la sociedad. La ética protestante, que cargaba su acento sobre el esfuerzo individual más que en la obra colectiva del común apoyo de los hombres hacia la divinidad y a través del amor, dirigió sus esfuerzos no a la lucha contra la pobreza en cuanto tal, sino a la eliminación de los pobres en particular. La moderna filantropía y las formas capitalistas del siglo pasado recibieron así del protestantismo buena parte de sus principales fundamentos ${ }^{15}$.

\footnotetext{
${ }^{13}$ Vide Jaime GUASP, "La beneficencia como objeto formal de la actividad administrativa", Es tudios en homenaje a Jordana de Pozas, Instituto de Estudios Políticos, Madrid, 1962, p. 319: «La beneficencia no deja de serlo porque el Estado atiende a esa necesidad presionado por la opinión pública o para alcanzar objetivos distintos a los del estricto favorecimiento del prójimo. En cambio, en la filantropía y en la caridad el espíritu inspirador de la actividad del filántropo y del caritativo es absolutamente preciso para definir la actitud de uno y otro: el que hace obras sociales para adquirir importancia en la colectividad o para disminuir la carga fiscal que pesa sobre él, no puede decirse que sea en realidad un hombre movido ni por el laico amor al prójimo que es la filantropía ni por el santo amor al prójimo que es la caridad».

${ }^{14}$ Vide Concepción ARENAL, La beneficencia, la filantropía y la caridad, o.c., p. 235.

15 Vide Ramón MARTÍN MATEO, Guía de actividades públicas asistenciales. La asistencia social co mo servicio público, Ministerio de la Gobernación, Madrid, 1967, p. 19.
} 


\subsubsection{Sociedades de asistencia, mutualidad o monte píos.}

En el siglo XVIII las clases populares urbanas para luchar contra la enfermedad y el infortunio organizaron Hermandades y Cofradías de socorro, la mayor parte de las cuales estaban vinculadas a gremios profesionales. Los miembros de las cofradías pagaban una inscripción y cuotas obligatorias, cuya periodicidad variaba según la cofradía (semanal, mensual, anual). Las prestaciones de las hermandades variaban desde la ayuda continuada en caso de enfermedad, incluyendo hospitalización, hasta la entrega de una cantidad única, previa certificación de la enfermedad ${ }^{16}$.

Las mutualidades son las asociaciones que con la denominación o con cualquier otra y sin ánimo de lucro ejercen una modalidad de previsión de carácter social o benéfico, encaminada a proteger a sus asociados o sus bienes contra circunstancias o acontecimientos de carácter fortuito y previsible, a los que están expuestos mediante aportaciones directas de los asociados o procedentes de otras entidades o personas protectoras ${ }^{17}$.

\subsubsection{Hospicios y casas de misericordia.}

La palabra hospicio viene de la latina hospitium, hospedería, de hospes, huésped. En realidad, hospes está pro hosti-pes, que era el que protegía al extranjero, y de ahí hospitium y hospitari. El nombre de hospes también se aplicó más tarde al que recibe la hospitalidad. Nuestra Real Academia dice que hospicio es la "casa destinada a albergar y recibir peregrinos pobres". También lo dice así el artículo 12 del reglamento de 14 de mayo de 1852. No hubo, sin embargo, precisión y uniformidad en el uso de tal palabra, ni la hay aún ${ }^{18}$.

Por casas de misericordia se entienden todas las destinadas para morada o asilo de alguna clase de pobres, que por su corta o crecida edad, o por cual-

\footnotetext{
16 Vide Manuel HERRERA GÓMEZ, Los orígenes de la intervención estatal en los problemas sociales, Escuela Libre Editorial, Madrid, 1999, p. 436.

17 Vide F. LÓPEZ-NIETO y MALLO, Las asociaciones y su normativa legal, Ediciones Abella. El consultor, Madrid, 1980, pp. 36-284.

18 Vide M. FERNÁNDEZ y FERNÁNDEZ, La beneficencia pública y los hospicios, Establecimientos Tipográficos de Jaime Ratés, Madrid, 1923, pp. 33-122.
} 
quier otra circunstancia estén inválidos o convenga a la causa pública y particular vivan reunidos por algún tiempo. Los reclusorios de niños huérfanos o desamparados, de ancianos lisiados, de viudas y de cualquier persona miserable, son casas de misericordia. También lo son los hospitales de enfermos, las inclusas o casas de expósitos y las galeras y casas de corrección para hombres y mujeres pobres; porque la corrección dice Sto. Tomás (Suma Teológica 2ª , 2ae, quest 33, art. I) que es verdadera limosna espiritual. Según el mayor, o menor número de especies y clases de necesitados a que se extiende o redujere alguna casa de misericordia, será más general o particular ${ }^{19}$.

\subsubsection{Pobreza.}

Esta palabra en sentido genérico, expresa solamente una idea relativa, pues se contrae a la clase de la sociedad que sufre mayores privaciones y disfruta menores goces ${ }^{20}$. Y surge de modo virulento, especialmente, en casos de enfermedad:

«La enfermedad era un auténtico drama para el trabajador dependiente de un salario, las más de las veces aleatorio dado su nexo con los cambios coyunturales. Afirmación que podemos constatar al examinar la desbordada demanda de los hospitales y centros benéficos en los períodos críticos, ya de por sí repletos y saturados en su trayectoria diaria. De ahí que, aunque muchos individuos reúnan, en principio, las condiciones imprescindibles para ingresar en las instituciones benéficas -ser pobres y, además, estar enfermos, no siempre consigan acomodo en ellas. Si a esto añadimos los convalecientes, por lo común, dados de alta de los hospitales sin las condiciones físicas para su inmediata reinserción en el mundo del trabajo, los enfermos de nacimiento (inválidos, impedidos, mutilados) o los lisiados por percances o accidentes laborales, comprenderemos el espesor que alcanza esta nube humana. La palpable y crónica incapacidad asistencial de la sociedad propicia, como única salida, la limosna; el oficio de pedir y mendigar.

\footnotetext{
${ }^{19}$ Vide Pedro Joaquín de MURCIA, Discurso político sobre la importancia y necesidad de los hospicios, casas de expósitos y hospitales, Madrid, 1798, p. 2.

${ }^{20}$ Vide J. ARIAS MIRANDA, Reseña histórica de la beneficencia española, o.c., p. 76. Vide Elena MAZA ZORRILLA, Pobreza y asistencia social en España, Siglos XVI-XX, Universidad de Valladolid, Valladolid, 1987, p. 15, donde establece las distintas acepciones asignadas a los términos: pobre, mendigo y vagabundo.
} 
Comprobamos por tanto, cómo entre la pobreza y la mendicidad -tal y como adelantábamos- no existen diferencias esenciales sino diferencias de grado. La práctica de la mendicidad es una opción, una alternativa constante en el mundo de los pobres, profundamente enraizada en él y a la que cualquiera puede verse abocado en un momento crítico. Incluso, es muy frecuente en testimonios escritos contemporáneos la confusión entre ambos términos, el uso indiscriminado de la palabra "pobre" o "mendigo"»"

José Campillo, ministro de Hacienda desde 1738 y secretario de Estado, Marina, Guerra e Indias desde 1740, en su obra "Lo que hay de más y de menos en España para que sea lo que debe ser y no lo que es", se enfrenta con el mundo de la necesidad material. La pobreza, la mendicidad ${ }^{22}$ y la vagancia son cuestiones que encuadra dentro de los fallos de la estructura socio-económica del país ${ }^{23}$.

\footnotetext{
${ }^{21}$ Ibídem, pp. 21-22. En la p. 47, nota 63 llega a afirmar: «En el siglo XVII el tratadista que con mayor profusión estudia la etiología de la pobreza es Fernández Navarrete. En su obra Conserva ción de Monarquías y discursos políticos (Madrid, 1626) reflexiona sobre las fluctuaciones monetarias y su papel multiplicador de los falsos mendigos: "[...] y no sólo ha convidado a los españoles a seguir la mendiguez la subida del vellón, sino también ha llamado y ha traído a estos reinos toda inmundicia de Europa, sin que haya quedado en Francia, Alemania, Italia y Flandes y aun en las islas rebeldes, cojo, manco, tullido o ciego que ho haya venido a Castilla, convidados de la golosina de ser tan caudalosa granjería el mendigar donde la moneda es de tanto valor"».

${ }^{22}$ Vide M. PEREZ QUINTERO, Pensamientos políticos y económicos dirigidos a promover en España la agricultura y demás ramas de la industria a extinguir la ociosidad y dar ocupación útil y honesta de todos los brazos, Madrid, 1798, p. 296: «Con esta que vuestra merced llama inhumanidad, les aseguramos pan de por vida, los libertamos de ir a servir al Rey, y que no los maten en la guerra: les proporcionamos a ellos una dulce industria para vivir alegremente y sin fatiga, cantando, tañendo y bailando, y paseándose, sin perder fiestas, fandangos, diversiones, ni función alguna; y a nosotros el consuelo de tenerles siempre en nuestra compañía, para que sean el báculo de nuestra vejez y las delicias de la vida». Vide Marcel BATAILLON, Erasmo y el erasmismo, Traducción castellana de Carlos PUJOL, Editorial Crítica, Barcelona, 1978, p. 186, donde refleja el horror moral y físico que experimenta Vives ante la mendicidad profesional.
}

${ }^{23}$ Vide Manuel HERRERA GÓMEZ, Los orígenes de la intervención estatal en los problemas sociales, Escuela Libre Editorial, Madrid, 1999, pp. 63-64: Para él, los pobres se dividen en tres categorías «1. Los "verdaderos pobres", "verdaderos infelices que, o ya destituidos de remedio a sus habituales dolencias, o ya tolerando las dilatadas muertes, solicitan el reparto de su hambre en la compasión del público".

2. Los "pobres por su conveniencia", aquellos vagos y holgazanes que huyen del trabajo y se refugian en la limosna por pura ociosidad.

3. Y los "pobres en apariencia" que realmente no lo son y utilizan este disfraz para ocultar sus fechorías. 


\subsubsection{Miseria.}

Se expresa con este significante un estado de pobreza que adquiere permanencia, producto de la indigencia y de la imposibilidad de salir de ella ${ }^{24}$.

\subsubsection{Indigencia.}

Esta voz manifiesta por el contrario una idea absoluta: aquel grado de miseria que supone la falta de las cosas más necesarias para la vida; y de consiguiente la precisión de acudirla con socorros ${ }^{25}$.

De acuerdo con estas categorías formula las soluciones:

a) Para los primeros, los verdaderos pobres, plantea su recogimiento en Hospicios, proporcionándoles cobijo y manutención en régimen abierto.

b) En cuanto a los pobres por su conveniencia, aboga por su integración forzosa en el mundo del trabajo productivo.

c) En referencia a los terceros, los pobres en apariencia, el castigo y presidio por los delitos que cometan.

Como instrumento imprescindible para aplicar sus alternativas, considera necesario e indispensable la creación de nuevos hospicios dotados de fábricas y talleres, así los acogidos en tales instituciones contribuirán a los gastos de su mantenimiento y asistencia.

Sobre los resultados de estos planteamientos no puede manifestarse más optimista; se sitúa en una línea que entronca plenamente con la literatura arbitrista del siglo XVII español: "A pocos años de su planificación estaría España desconocida del ocio, limpia de abandonados y vagos, y floreciente en toda clase de ejercicio y ocupaciones"».

${ }^{24}$ Vide J. ARIAS MIRANDA, Reseña histórica de la beneficencia española, o.c., p. 76. Vide Elena MAZA ZORRILLA, Pobreza y asistencia social en España, Siglos XVI-XX, Universidad de Valladolid, Valladolid, 1987, p. 13: «[...] la indigencia equivale al estado en el cual las necesidades esenciales, de forma intermitente, no pueden ser satisfechas, y la miseria es la indigencia permanente. Cuando esta miseria afecta a un conjunto de individuos, a una parte de la población, podemos hablar con rigor de pauperismo».

${ }^{25}$ Vide J. ARIAS MIRANDA, Reseña histórica de la beneficencia española, o.c., p. 76. Vide Elena MAZA ZORRILLA, Pobreza y asistencia social en España, Siglos XVI-XX, Universidad de Valladolid, Valladolid, 1987, p. 52: «Don Carlos y Doña Juana mandan que sólo los verdaderos pobres puedan pedir limosna, circunscrita a los pueblos de su naturaleza y jurisdicción o un radio de seis leguas a la redonda. Deberían llevar -excepto los ciegos- cédula del párroco con su nombre y señas personales, visada por la justicia. [...]. Las Cortes de Valladolid de 1555 solicitan a Felipe II que a las leyes vigentes sobre mendigos se añada la constitución en todos los pueblos de un "padre de pobres", encargado de proporcionar ocupación, remedio y cura a cuantos lo necesiten. En parte, el monarca satisfizo estos deseos. Por Pragmática del 7 de agosto de 1565 (ley XIV) se organizan los "diputados de parroquia", dos "personas buenas" de cada feligresía ocupadas en averiguar y buscar a los mendigos, distinguir los impedidos y decrépitos, proveerlos de licencias para pedir (visadas por el párroco y confirmadas por la justicia) y, previo registro, del socorro material de los pobres vergonzantes». 


\subsection{La gestión de monopolios ocupacionales en manos de los invidentes ${ }^{26} 27$.}

Los ciegos de Zaragoza (primeras ordenanzas en 1537) consiguieron el monopolio de una actividad muy peculiar, cual era la de recitar y cantar oraciones a domicilio. En caso de enfermedad, y mientras ésta se prolongase, los mayordomos de la cofradía se encargarían de que otros ciegos visitaran a los parroquianos del enfermo, con el fin de que "la tal deuocion (devoción) de los dichos perrochianos no se aya de perder". El enfermo recibiría de los suplentes sus sueldos íntegros. Esta cofradía tenía facultad de multar a cualquier otra persona ajena, ciega o no, que cantara u orara a domicilio, con la excepción de los miembros de la Iglesia ${ }^{28}$.

${ }^{26}$ Vide Jesús MONTORO MARTÍNEZ, Los ciegos en la historia, Tomo I, ONCE, Madrid, 1991, pp. 561-564: «Durante la Edad Media se hicieron famosos "Los romances del cordel”, coplas y recetas que llevaban los ciegos sujetas a un cordel y colgando en la pechera para venderlas por las casas a distintos precios, al mismo tiempo que explotaban los sentimientos y aficiones de sus moradores para obtener mejores beneficios. Formaban hermandades en los grandes núcleos de población para distribuirse por sectores las manzanas de casas o las calles donde debía postular cada hermano, y llevaban un cencerro para anunciar su presencia a los posibles clientes y exigir a los ciegos intrusos que abandonasen el lugar, pues de lo contrario serían severamente castigados por los corregidores del municipio, que siempre solían ser los hermanos mayores de estas cofradías. $[\ldots]$....

En 1314 se fundó en Valencia la cofradía de "Los ciegos oracioneros", cuyos miembros se encargaban de dirigir el resto del rosario y demás responsorios en los velatorios, triduos, novenas y otros actos devotos que se ofrecían por el alma de quien acababa de morir. [...].

En 1329 se constituyó en la ciudad del Turia una asociación de mendigos que determinaba los puestos donde cada miembro debía postular y le cobraba una cuota para tener un fondo con el que atender a sus asociados en caso de enfermedad y pagar su sepelio. [...].

En 1329 se crea en Barcelona la cofradía "El cecs trovadors", que agrupa a los privados de vista músicos y poetas de la Ciudad Condal para concertar los contratos laborales y distribuir adecuada y oportunamente el trabajo. [...].

A finales del siglo XIV, algunos ciegos de Zaragoza formaron una sociedad de recaderos, trajinantes y ordinarios, cuyo cometido era llevar mercancías, cartas y mensajes a los pueblos de esta provincia, $[\ldots] »$.

27 Vide Marcel BATAILLON, Erasmo y el erasmismo, Traducción castellana de Carlos PUJOL, Editorial Crítica, Barcelona, 1978, p. 188: «Vives enumera con visible complacencia los múltiples trabajos que pueden realizar los ciegos. No sólo ciertos estudios y la música están a su alcance, sino que los hombres pueden manejar tornos o prensas, accionar fuelles de forja, confeccionar cajas, jaulas, cestos; las mujeres pueden hilar y devanar».

${ }^{28}$ Vide Roberto GARVIA SOTO, La organización nacional de ciegos. Un estudio institucional, Centro de Estudios Avanzados en Ciencias Sociales, Madrid, 1993, p. 24. 
Los ciegos de Madrid (primeras ordenanzas de 1614) también disfrutaban de su propio monopolio ocupacional. De hecho, disfrutaban de dos monopolios: la venta de gacetas, diarios, almanaques, guías y toda suerte de pequeños folletines; y el ejercicio público de la música. Al mismo tiempo, la Hermandad era una sociedad funeraria ${ }^{29}$ para los madrileños no ciegos. A finales del siglo XVIII, esta hermandad era uno de los gremios más prósperos de la villa.

Algunas fuentes literarias relatan, aun con tonos cómicos que muestran un cierto desapego, e incluso desprecio por aquel modo de vida (o de supervivencia), los afanes de los ciegos madrileños en aquellas dos actividades. Respecto a la venta de la Gaceta, el acontecer era el siguiente ${ }^{30}$ :

“[...] solía suceder que llegase a Madrid un correo gabinete con pliegos para la Secretaría de Guerra; como por ensalmo cundía entre aquellos (ciegos) la noticia, y paso a paso, iban agrupándose en torno a la Imprenta Real o Nacional, según los tiempos, y allí aguardaban una, dos, tres o más horas, hasta que se abría el despacho; se abalanzaban frenéticos a la reja y adquirían unas cuantas decenas de gacetas extraordinarias: desde allí se dividía la numerosa falange con rumbo a los cuatro vientos y diseminados los ciegos corrían como energúmenos, aturdiendo los oídos del pacífico ciudadano, y perdiendo de vender su género en fuerza de andar deprisa y de los gritos de sus colegas, que tampoco querían hacer alto hasta que se apoderaran de una calle donde campeasen solos. Perspectiva por entonces animada presentaba la Puerta del Sol con todas sus avenidas; todo era ir y venir ciegos y arrebatarles la noticia a puñadas, y formarse grupos, donde se recogían con avidez las palabras del que leía”.

Respecto a la música callejera, el relato tampoco está libre de una cierta jocosidad hostil:

"Lleva nuestro ciego una guitarra, o mejor dicho la guitarra le conduce a él, que ocupándole las dos manos y no pudiendo hacer caso de su palo, especie de péndulo ondulatorio, las armoniosas cuerdas que pulsan sus

\footnotetext{
${ }^{29}$ Vide Juan Francisco PÉREZ GÁLVEZ, El sistema funerario en el derecho español, Aranzadi, Pamplona, 1997.

${ }^{30}$ Vide Roberto GAVIA SOTO, La organización nacional de ciegos. Un estudio institucional, o.c., pp. 24-26.
} 
delicados dedos son un aviso significativo y le salvan las dificultades que a su lento y sereno paso se le oponen. Y nada importa que en vez de guitarra lleve violín, que a aquel que nada ve, la naturaleza nos dice que habrá de tocar bien. Mira lector a nuestro hombre en la calle de Toledo en la puerta de San Isidro el Real, cercado de una porción de curiosos que así tienen la boca abierta, como el ciego la vista tapada, el palo colgado de un botón, el recado de las coplas al cuello, la capa sujeta al mismo, aunque echada atrás, el instrumento en actitud de obrar, y boca y manos, y cabeza y pies, diciendo y haciendo sin pies ni cabeza, aunque con tanto gesticulación y dificultosas caras, como quien quiere marcar, con el rostro, lo que los ojos no pueden, pero quisieran decir” ${ }^{31} 32$

La eliminación de privilegios existentes en favor de los ciegos en el antiguo régimen, se produce a través de una serie de leyes emitidas a finales del siglo XVIII y comienzos del siglo XIX. Así con la Real Orden de 5 de abril de 1795, y Real Cédula de 29 de enero de 1804, se derogaban las exenciones que los ciegos tenían acerca del pago de contribuciones, alcabalas, arbitrios y cientos. Esta eliminación de privilegios, se completaría en la Novísima Recopilación de Leyes, sancionada por Real Cédula de Carlos IV el día 15 de julio de 1805, en los siguientes términos: "los ciegos por serlo no deben gozar de inmunidad personal o eclesiástica, ni tampoco son exentos de contribuciones reales en los frutos de labranza, sean de haciendas de su propiedad o arrendadas, ni por sus comercios y granjerías, antes han de estar sujetos a lo que pagan los demás vasallos legos" (ley 30 del título XVIII del libro VI). Esta legislación se completaría con la Ley dada por Fernando VII en octubre de 1823: por la que se prohibían todas las sociedades que juzgó subversivas o inútiles, teniendo esta última consideración regia muchas asociaciones y gremios de ciegos existentes en el momento, con lo que, en el caso del colectivo de ciegos, quedaba legalmente zanjado el paso del antiguo al nuevo régimen.

\footnotetext{
${ }^{31}$ Ibídem, pp. 24-26. Vide Esther BURGOS BORDONAU, Historia de la enseñanza musical para ciegos en España: 1830-1938, ONCE, Madrid, 2004.

32 Vide La Niña de la Puebla, Milonga:

Noche eterna de mis ojos,

Luz en la sombra escondía;

yo vivo en la oscuridá

sin otra luz que mi vía;

luz y vía es mi cantar

como lágrima sentía».
} 
Con la pérdida de privilegios y la eliminación de su forma tradicional de asociación, muchos de estos minusválidos quedarán sometidos al régimen general de tratamiento de la mendicidad ${ }^{33}$.

\subsection{Los establecimientos de beneficencia, las rifas y el recogimiento de los ciegos}

1.4.1. Evolución histórica de la beneficencia y la afectación de los establecimientos pú blicos $^{34} 35$

Los principios liberales e individualistas alcanzarán su aplicación en España, sobre los planteamientos iniciales de los hombres de la Constitución de

33 Vide Valentín FORTÚN ARRIEZU, La creación e implantación de la Organización Nacional de Cie gos Españoles: 1938-1948, Universidad de Navarra, 1998, pp. 32-33.

34 Vide: José Luís SEBASTÍAN LÓPEZ, De la "utilitas pública” al interés público del artículo 35 del Código Civil, Tomo I, Universidad Complutense, Madrid, 1985, pp. 113-118: los establecimientos desde la época romana y su clasificación; Ibídem, Tomo II, p. 392: el sostenimiento de los establecimientos públicos, p. 560: el proyecto de Código Civil de 1851 y los establecimientos, p. 637: 1859, censo de establecimientos de beneficencia; Urbano VALERO AGUNDEZ, La fundación co mo forma de empresa, Universidad de Valladolid, Valladolid, 1969, p. 70: los establecimientos en el derecho romano.

35 Vide Concepción ARENAL, La beneficencia, la filantropía y la caridad, Memoria premiada por la Real Academia de Ciencias Morales y Políticas, Madrid, 1861, pp. 13-19, donde se encuentra el cuadro cronológico de los principales establecimientos de beneficencia en España, que por su interés, paso a reproducir:

\begin{tabular}{|l|c|c|c|}
\hline ESTABLECIMIENTO & $\begin{array}{c}\text { NOMBRE DEL } \\
\text { PUEBLO }\end{array}$ & $\begin{array}{c}\text { NOMBRE DEL } \\
\text { FUNDADOR }\end{array}$ & $\begin{array}{c}\text { ANO EN QUE } \\
\text { SE FUNDÓ }\end{array}$ \\
\hline Hospital de S. Juan & Oviedo & Alonso VI & 1058 \\
\hline Hospital & Cardona & D. Ramón Folch & 1083 \\
\hline Hospital de la Seo & Zaragoza & Doña Hodierna de la Fuente & 1152 \\
\hline Hospital del Rey & Burgos & Alonso VIII & 1212 \\
\hline Hospital de Santa Cruz & Barcelona & Varios vecinos & 1229 \\
\hline Alberguería & Oviedo & Doña Balesquida Giráldez & 1232 \\
\hline Hospital llamado de S. Juan de Dios & Alicante & D. Bernardo Gomir & 1333 \\
\hline Hospital & Teruel & Doña Magdalena de la Cañada & 1333 \\
\hline Hospital de Pobres & Vich & D. Ramón Terrados (comerciante) & 1347 \\
\hline Hospital de S. Bernardo & Sevilla & Varios sacerdotes sevillanos & 1355 \\
\hline Hospital de Sacerdotes pobres & Valencia & Cofradía de Nuestra Señora & 1356 \\
\hline Hospital de S. Miguel & Murviedro & D. Antonio Peruyes & 1367 \\
\hline Hospital de Huérfanos & Barcelona & D. Guillén de Pou & 1370 \\
\hline Hospital de las Misericordias & Guadalajara & Doña María López & 1375 \\
\hline
\end{tabular}




\begin{tabular}{|c|c|c|c|}
\hline Hospital de S. Cosme y Damián & Sevilla & Varios médicos y cirujanos & 1383 \\
\hline Hospital & Castellón & D. Guillermo Trullols & 1391 \\
\hline Hospital de Eu-Conill & Valencia & D. Francisco Conill & 1397 \\
\hline Hospital de Eu-Bou & Valencia & D. Pedro Bou & 1399 \\
\hline Hospital & Castrogeriz & D. Juan Pérez y su esposa & 1400 \\
\hline Hospital & Poza & D. Juan Lences & 1400 \\
\hline Hospital & Villafranca & Doña Juana Manuel & 1418 \\
\hline Hospital de S. Mateo & Sigüenza & D. Diego Sánchez (dignidad de la Catedral) & 1445 \\
\hline Hospital General & Palma de M. & Alonso V de Aragón & 1456 \\
\hline Hospital de S. Antonio de los peregrinos & Segovia & D. Diego Arias & 1461 \\
\hline Hospital de la Misericordia & Talavera & D. Fernando Alono & 1475 \\
\hline Casa de la Misericordia & Sevilla & D. Antonio Ruiz (sacerdote) & 1477 \\
\hline Hospital & Oña & D. Martín de Oña & 1478 \\
\hline Hospital de S. Juan & Burgos & Los Reyes Católicos & 1479 \\
\hline Hospital de la Misericordia & Alcalá de Henares & D. Luís Entezana y su esposa Doña Isabel de Guzmán & 1486 \\
\hline Antiguo Hospital del Campo del Rey & Madrid & D. García Alvarez de Toledo (Obispo de Astorga) & 1486 \\
\hline Hospital de Dementes & Valladolid & D. Santos Velazquez & 1489 \\
\hline Hospital de la Magdalena & Almería & D. Rodrigo Demandia y el Cabildo de la Catedral & 1492 \\
\hline Hospital de Santa Ana & Granada & Los Reyes Católicos & 1492 \\
\hline Hospital Real & Santiago & Los Reyes Católicos & 1492 \\
\hline Hospital de Santa Cruz & Toledo & D. Pedro González Mendoza & 1494 \\
\hline Hospital de la Misericordia & Segovia & D. Juan Arias (Obispo de la diócesis) & 1495 \\
\hline Hospital & Ponferrada & Los Reyes Católicos & 1498 \\
\hline Hospital de Nuestra Señora de Gracia & Tudela & D. Miguel de Eza & 1500 \\
\hline Hospital de S. Sebastián & Badajoz & D. Sebastián Montoro & 1500 \\
\hline Hospital & Lizarza & D. Domingo lbarrondo & 1500 \\
\hline Hospital de la Caridad & Olivenza & El Rey D. Manuel de Portugal & 1501 \\
\hline Hospital de S. Lucas y S. Nicolás & Alcalá de Henares & El Cardenal Cisneros & 1508 \\
\hline Hospital de los Viejos & Briviesca & D. Pedro Ruiz & 1513 \\
\hline Hospital de la Caridad & Granada & D. Diego San Pedro y D. Gaspar Dávila & 1513 \\
\hline Hospicio & León & D. Cayetano Cuadrillero (Obispo de la diócesis) & 1513 \\
\hline Hospital para forasteros & Quintanilla & D. Juan Martínez & 1524 \\
\hline Hospital del Obispo & Toro & D. Juan Rodríguez Fonseca (Arzob. de Burgos) & 1524 \\
\hline Hospicio & Tudela & D. Juan de Aragón y D. Pedro Gerónimo Ortiz & 1526 \\
\hline Hospital & Avilés & D. Pedro Solís & 1530 \\
\hline Hospital de Huérfanos & Zaragoza & Varios vecinos & 1543 \\
\hline Hospital General & Pamplona & El Arcediano D. Ramiro Goñi & 1545 \\
\hline Hospital de las Cinco Llagas & Sevilla & $\mathrm{D}^{\mathrm{a}}$ Catal. Rivera y su hijo D. Fadrique Enríquez & 1546 \\
\hline Hospital & San Sebastián & D. Pedro Fernández & 1550 \\
\hline Casa de Expósitos & Córdoba & El Deán D. Juan Fernández de Córdoba & 1552 \\
\hline Hospital de S. Juan de Dios & Madrid & El Venerable Antón Martín & 1552 \\
\hline Hospital de S. Juan de Dios & Castro del Rio & Licenciado D. Juan López Illescas & 1557 \\
\hline Hospital de Santiago & Oviedo & D. Gerónimo Velasco (Obispo de la diócesis) & 1560 \\
\hline Hospital de la Concepción & Burgos & D. Diego Bernuy & 1562 \\
\hline Antiguo Hospital de S. Millan & Madrid & Varias personas caritativas & 1565 \\
\hline Hospital de la Misericordia & Jaén & Cofradía de la Misericordia & 1570 \\
\hline Inclusa & Madrid & Cofradía de Ntra. de la Soledad & 1572 \\
\hline Hospital de S. Roque & Santiago & El Arzobispo D. Francisco Blanco & 1577 \\
\hline Inclusa & Jaén & D. Diego Valenzuela & 1582 \\
\hline
\end{tabular}


DOCUMENTOS

\begin{tabular}{|c|c|c|c|}
\hline Hospicio & Santiago & Hermandad de Ntra. Sra. de la Misericordia & 1583 \\
\hline Hospital de dementes & Toledo & D. Francisco Ortiz (Nuncio de S.S.) & 1583 \\
\hline Casa de Misericordia & Barcelona & Dr. D. Diego Pérez Valdivia & 1583 \\
\hline Hospital de Ntra. Sra. de los Remedios & Oviedo & D. Iñigo de la Rua (Abad de Teverga) & 1584 \\
\hline Hospital del Buen Suceso & Coruña & Ares González & 1588 \\
\hline Hospital General & Madrid & Felipe II & 1590 \\
\hline Casa de Arrepentidas & Palma de M. & Fray Rafael Serra & 1592 \\
\hline Antiguo Colegio de Desamparados & Madrid & Congregación del Amor de Dios & 1592 \\
\hline Obra pía para dar limosna & Castrojeriz & D. Sebastián Ladrón & 1594 \\
\hline Hospital de S. Juan de Dios & Segovia & D. Diego López & 1594 \\
\hline Hospital de S. Juan de Dios & Pontevedra & El Ayuntamiento & 1595 \\
\hline Colegio de Niños del Amor de Dios & Valladolid & D. Francisco Pérez Nájera & 1595 \\
\hline Hospital de S. Juan y S. Jacinto & Córdoba & D. Pedro del Castillo & 1596 \\
\hline Hospital de la Concepción & Bujalance & D. Martín López & 1604 \\
\hline \multirow[t]{3}{*}{ Refugio } & Madrid & El padre Bernardino de Antequera y los señores & \\
\hline & & D. Pedro Laso de la Vega, D. Juan Serra y & \\
\hline & & la Hermandad del Refugio & 1615 \\
\hline Casa de la Caridad & Salamanca & D. Bartolomé Caballero & 1623 \\
\hline Hospital de Sacerdotes & Sevilla & La Hermandad de Jesús Nazareno & 1627 \\
\hline \multirow[t]{2}{*}{ Hospital de S. Julián y S. Quirce } & Burgos & D. Pedro Barrantes y D. Gerónimo Pardo & \\
\hline & & (Abad de San Quirce) & 1627 \\
\hline Hospital & Zamora & Los señores D. Isidro y D. Pedro Morán. & 1629 \\
\hline \multirow[t]{2}{*}{ Hospital de S. Pablo } & Barcelona & Doña Lucrecia Gualba, Doña Victoria Aslor, & \\
\hline & & Doña Elena Soler y D. Pablo Ferranz & 1629 \\
\hline Obra Pía para dotar doncellas huérfanas & Burgos & Doña Ana Polanco & 1630 \\
\hline Hospital & Tornavacas & Licenciado D. Tomás Sánchez & 1633 \\
\hline \multirow[t]{2}{*}{ Hospital de Mujeres } & Cádiz & D. Juan Just, D. Manuel Yliberry, & \\
\hline & & Doña Jacinta Armengol (Marquesa de Campo Alegre) & 1648 \\
\hline Hospital de Ntra. Sra. de la Piedad & Nájera & Una Congregación & 1648 \\
\hline Hospicio & Zaragoza & Los hermanos de la Escuela de Cristo & 1666 \\
\hline Colegio de la Paz & Madrid & La Duquesa de Feria & 1669 \\
\hline Casa de Misericordia & Valencia & La Ciudad & 1670 \\
\hline Hospital de Jesús Nazareno & Córdoba & El Reverendo Cristobal de Santa Catalina & 1673 \\
\hline Hospicio & Madrid & El beato Simón de Rojas & 1674 \\
\hline Casa de Misericordia & Palma de M. & La Ciudad & 1677 \\
\hline Hospital de la Orden Tercera & Madrid & La Orden y Doña Lorenza de Cárdenas & 1678 \\
\hline Hospital de S. Julián & Málaga & Varias personas principales & 1682 \\
\hline Hospital de Convalecencia & Toro & D. Félix Rivera y su esposa D’a Teresa Sierra & 1699 \\
\hline Casa de Misericordia & Pamplona & El Ayuntamiento & 1700 \\
\hline Hospital del Cardenal & Córdoba & El Cardenal D. Pedro Salazar (Obispo de Cardona) & 1701 \\
\hline Hospital & S. Sebastián & La Ciudad & 1714 \\
\hline Hospital de Jesús Nazareno & Castro del Rio & D. Tomás Guzmán & 1741 \\
\hline Casa de Misericordia & Alicante & D. Juan Elías Gómez & 1743 \\
\hline Casa del Retiro & Barcelona & D. Gaspar Sanz y la Congreg. de la Esperanza & 1743 \\
\hline Hospital & Torrellas & D. Pedro Tudela (médico de la Villa) & 1746 \\
\hline Hospicio & Jaén & Fray Benito Masin (Obispo de la diócesis) & 1751 \\
\hline Hospital & Undues de Lerda & D. Matías García & 1751 \\
\hline Casa de Misericordia & Murcia & El canónigo D. Felipe Munise & 1752 \\
\hline Hospicio & Salamanca & Fernando VI & 1752 \\
\hline
\end{tabular}


Cádiz, cuando se puso en marcha el proceso desamortizador. Para el caso concreto de los Ayuntamientos, el párrafo VI del art. 321 establecía:

«Estará a cargo de los Ayuntamientos el cuidado de los hospitales ${ }^{36}$, hospicios, casas de expósitos y demás establecimientos de beneficencia, bajo las reglas que se prescriban».

\begin{tabular}{|c|c|c|c|}
\hline Hospicio Provincial & Oviedo & D. Isidoro Bil (Regente de la Audiencia) & 1752 \\
\hline Casa de Misericordia & Valladolid & Varios vecinos & 1752 \\
\hline Hospicio & Badajoz & Fernando VI & 1757 \\
\hline Hospicio & Cádiz & La Hermandad de la Caridad y el Marqués del Real Tesoro & 1763 \\
\hline Hospital de S. Fernando & Coruña & D. Tomás del Valle (Obispo de Cádiz) & 1768 \\
\hline Hospital de Carretas & Santiago & D. Bartolomé Rajoy (Arzobispo de la diócesis) & 1770 \\
\hline Casa de Misericordia & Tudela & Doña María de Hugarte & 1771 \\
\hline Inclusa & Vitoria & Una Asociación & 1780 \\
\hline Hospital de la Caridad & Ferrol & La Villa y el Sarg. Mayor D. Dionisio Sánchez & 1780 \\
\hline Hospital & Villalengua & Doña Josefa Vera & 1780 \\
\hline Hospital & Erla & D. Pedro Castrillo & 1782 \\
\hline Hospicio & Cuidad-Real & D. Francisco Lorenzana (Arzobispo de Toledo) & 1784 \\
\hline Casa de Expósitos & Mondoñedo & D. Francisco Cuadrillero (Obispo de la diócesis) & 1786 \\
\hline Casa de Huérfanos de S. Vicente & Castellón & D. José Climent (Obispo de Cardona) & 1789 \\
\hline Hospital de la Ciudad & Coruña & La Congregación del Espíritu Santo y Doña Teresa Herrera & 1791 \\
\hline Casa de Misericordia & Teruel & D. Feliz Rico (Obispo de la diócesis) & 1798 \\
\hline Casa de Expósitos & Palma de M. & D. Bernardo Noval y Crespi (Obispo de la diócesis) & 1798 \\
\hline Hospicio & Astorga & El Deán D. Manuel Revilla & 1799 \\
\hline Casa de Caridad & Barcelona & El Capitán General Duque de Lancaster & 1803 \\
\hline Hospital de mujeres incurables & Madrid & La Condesa Viuda de Lerena & 1803 \\
\hline Hospital de S. Rafael & Santander & D. Rafael Omás Menéndez (Obispo de la diócesis) & 1803 \\
\hline Casa de Expósitos & Pamplona & D. Joaquín Uriz (Obispo de la diócesis) & 1803 \\
\hline Casa de Caridad & Vergara & El Ayuntamiento & 1806 \\
\hline Hospicio & Córdoba & D. Pedro Trevilla (Obispo de la diócesis) & 1807 \\
\hline Hospital & Bilbao & La Villa & 1818 \\
\hline Casa de Beneficencia & Valladolid & El Capitán General C. Carlos O’Donell & 1818 \\
\hline Casa de Caridad & Santander & El Ayuntamiento & 1820 \\
\hline Casa de Beneficencia & Castellón & El Ayuntamiento & 1822 \\
\hline Casa de Caridad & Vich & Una Junta & 1832 \\
\hline Asilo de S. Bernardino & Madrid & El Corregidor Marqués de Pontejos & 1834 \\
\hline Casa de Expósitos & Coruña & El Jefe Político, D. José Martínez, y el Ayuntamiento & 1844 \\
\hline Casa de M̊ㅗㅇ. Sma. de las Desamparadas & Madrid & La Sra. Vizcondesa de Jorbalán & 1845 \\
\hline Hospital de hombres incurables & Madrid & El Gobernador D. Melchor Ordoñez & 1852 \\
\hline
\end{tabular}

${ }^{36}$ Vide José ORTIZ DÍAZ, "Hacia una reordenación de la sanidad pública española: el problema hospitalario", RAP, 51, (1966), pp. 154-160, donde expone una interesantísima evolución histórica de los hospitales: «El hospital de Occidente fue durante tiempo -siglos IV al XII-, en muchos casos, un hotel gratuito e indiferenciado para acoger a los pobres y cuidar a los enfermos. [...]. Desde el siglo XII a la Reforma, las fundaciones de hospitales en Europa se multiplicaron extraordinariamente y el hospital como institución alcanzó gran importancia. Su erección por los reyes y señores feudales, cofradías religiosas, corporaciones o gremios, particulares o por los obispos, 
Corresponderá a las Diputaciones (art. 335, párrafos II y VIII) ${ }^{37} 38$ :

«Velar sobre la buena inversión de los fondos públicos de los pueblos y examinar sus cuentas, para que, con su visto bueno, recaiga la aprobación superior, cuidando de que en todo se observen las leyes y reglamentos $[\ldots]$.

Cuidar de que los establecimientos piadosos y de beneficencia llenen su respectivo objetivo, proponiendo al gobierno las reglas que estimen conducentes para la reforma de los abusos que observaren» ${ }^{39}$.

obedecía en muchos casos a una motivación religiosa. [...]. El hospital -y nos referimos fundamentalmente al europeo en la época citada- constituyó un establecimiento principalmente benéfico más que sanitario, para indiferentemente recoger y atender a los pobres, a los inválidos, a los peregrinos y curar gratuitamente a los enfermos indigentes.

Los famosos "hôtels-Dieu" (o "Maissons-Dieu") fueron establecimientos generalmente no especializados, donde se recibían no sólo a los enfermos, sino también a los pobres, a los peregrinos, a las mujeres arrepentidas.

En la historia de muchos de los hospitales españoles se observa la mezcla de enfermería, asilo y hospedería, y también su causalidad caritativo-cristiana».

37 Vide Instrucción para la administración y gobierno de los establecimientos de beneficencia general de 27 de enero de 1885. art. 3: «Son establecimientos de Beneficencia general y funcionan como tales: 1. El Hospital de la Princesa, establecido en Madrid, con destino al albergue de enfermos de padecimientos agudos; 2. Los hospitales de los enfermos incurables o decrépitos, establecidos también en Madrid bajo la denominación de Jesús Nazareno y Nuestra Señora del Carmen. 3. El hospital de decrépitos y ciegos de ambos sexos, denominado del Rey, establecido en Toledo. 4. El hospital-manicomio de Santa Isabel, de Leganés. 5. El hospital hidrológico de Carlos III, establecido en Trillo (Guadalajara). 6. El Colegio de Ciegos de Santa Catalina de los Donados, de Madrid. 7. El Colegio de huérfanos denominados en La Unión, en Aranjuez».

${ }^{38}$ El Estatuto provincial de 1925 determinaba que los establecimientos hospitalarios provinciales se incluyen bajo la rúbrica de acción o servicios de Beneficencia. Y así, entre las obligaciones mínimas de las Diputaciones provinciales en materia de beneficencia (art. 127) se señalan las siguientes: «A) Sostenimiento por lo menos de una Casa provincial de Maternidad y Expósitos. B) Sostenimiento de una Casa de Beneficencia hospitalaria. [...]. D) Sostenimiento de una Casa de Caridad, para reclusión de dementes pobres».

39 Vide Manuel HERRERA GÓMEZ, Los orígenes de la intervención estatal en los problemas sociales, Escuela Libre Editorial, Madrid, 1999, pp. 170-171: «Esta municipalización de la beneficencia efectuada por la Constitución gaditana responde a dos motivos fundamentales. En primer término, a la pronta transformación de la pobreza. Esta es cada vez más urbana y menos rural; en consecuencia, no cabía otra solución que reforzar la capacidad urbana de asistencia. La antigua asistencia centrada en enfermos, expósitos y vagos itinerantes se muestra insuficiente, los nuevos beneficiarios serán las masas de jornaleros que invaden las ciudades y amenazan con desbordar la precaria dotación municipal para controlar la vida urbana. [...]. 
La Ley de 27 de septiembre de 1820 atacó a las Iglesias y demás establecimientos similares, eclesiásticos o laicos que se agrupaban como "manos muertas", iniciando así el régimen de la desvinculación. El Estado se vio obligado a cubrir las funciones de beneficencia que estaban atendidas por dichas entidades y, acaso consciente de sus limitaciones administrativas, y sobre todo económicas, empezó a sentar las bases que llevarían a la distinción entre beneficencia pública y beneficencia privada al hablar, por una parte, de la "beneficencia general" y, por otra parte, de la llamada "beneficencia particular". Esta última se mantendrá con altibajos y, siempre sometida a un régimen cautelar que se completará en la función de tutela a cargo de la Administración pública.

El resultado llegó a ser el siguiente: el Estado desarrollará directamente ciertos servicios mediante los denominados "establecimientos públicos" en régimen de prestación directa, pero, además, ejercerá un control sobre la beneficencia privada, para la que exigió la previa constitución de una persona jurídica del tipo "fundación" sobre la que ejercía la tutela administrativa (régimen de protectorado). La Ley de 27 de diciembre de 1821 y, sobre todo, la Ley de 20 de julio de 1849 darán como resultado este régimen jurídico ${ }^{40}$. El concepto central será el siguiente:

«Los establecimientos de beneficencia son públicos. Se exceptúan únicamente, y se consideran como particulares si cumpliesen con el objeto de su fundación, los que se costeen exclusivamente con fondos propios, donados o legados por particulares, cuya dirección y administración esté confiada a corporaciones autorizadas por el Gobierno para este efecto a patrones designados por el fundador [...]» (Ley de 1849, art. 1).

La citada Ley de 20 de junio de 1849 organizó la beneficencia pública. La beneficencia privada se reguló por el Decreto e Instrucción de 27 de abril de 1875, que fue sustituido por el Real Decreto e Instrucción de 14 de marzo de 1899, que recogía las modificaciones de 27 de enero de 1865, de 1879, de 1881, de 1885, etc. Tanto la Ley de 1849 como las normas integradas en 1899 han constituido, básicamente, la legislación vigente en la materia. Las modifi-

Un segundo elemento que explica esta municipalización es la imposibilidad de la Iglesia para realizar la función asistencial que tradicionalmente había mantenido como propia, imposibilidad que se encuentra fundamentada en la desamortización de los patrimonios de los establecimientos asistenciales y conventos, proveedores regulares de ayudas. [...]».

40 Vide Efrén BORRAJO DACRUZ, "De la previsión social a la protección en España: bases histórico-institucionales hasta la constitución”, Revista de Economía y Sociología del Trabajo, 1, (1989), p. 28. 
caciones posteriores afectarán al régimen económico, rendición de cuentas, etc., pero, sobre todo, dividirán el régimen del patronato, atribuido en principio al Ministerio de la Gobernación, entre otros Ministerios según la especialización de la fundación tutelada ${ }^{41}$.

\subsubsection{La expresión "establecimiento público" en el derecho comparado.}

Inicialmente la expresión establecimiento público en el derecho francés aludía simplemente al hecho de que determinadas finalidades de un marcado carácter técnico eran prestadas por la Administración (fundamentalmente por los entes locales) en régimen de establecimiento, esto es, en unas organizaciones ad hoc de elementos personales y reales, aptos para satisfacer dichos fines. Esta calificación supone fundamentalmente una contabilidad especial y una cierta autonomía financiera y patrimonial, autonomía más de hecho que jurídica, pues jurídicamente dichas organizaciones no son sino órganos del Estado (o de las colectividades locales), que por sus funciones características no pueden ajustarse por completo a las reglas contables de éste. La entidad de dichos establecimientos es la de una unidad organizativa, que financieramente se configura como una caja especial ${ }^{42}$.

En Francia, la ampliación del concepto de establecimiento público, se produce por el rechazo de la Revolución hacia los cuerpos intermedios. De modo, que se niega a las personas jurídico privadas la capacidad de recibir liberalidades (donaciones y legados). Solamente las personas morales públicas gozan de este derecho, en virtud de un reconocimiento legal (declaración de utilidad pública); es así como se forzará la necesidad de obtener un reconocimiento como "establecimiento de utilidad pública" a toda una serie de personas puramente privadas.

Sin embargo, las necesidades a que había respondido la constitución orgánica de la sociedad anterior a la revolución tenían realidad y volvieron a resurgir (colegios de abogados y procuradores, asociaciones de riego, etc.) y el resultado fue su calificación como "establecimientos públicos", y no de "utilidad pública", porque éstos eran entes puramente privados de tipo fundacional. Por tanto, con este nombre se designaban dos tipos de entes muy diferentes $^{43}$ : unos (los originarios) que eran auténticos servicios estatales; y otros, entes representantitos de intereses sociales, ajenos y exteriores al Estado (fue-

\footnotetext{
${ }^{41}$ Ibídem, p. 28.

42 Vide Gaspar ARIÑO ORTIZ, "Sobre el concepto y significado institucional de la expresión «establecimiento público»”, Documentación Administrativa, 155, (1973), pp. 9-10.
} 
ra de su organización $)^{44}$.

Debe destacarse que la función que se atribuye a dichos establecimientos públicos es la gestión de servicios que tienden a la satisfacción de intereses generales ${ }^{45}$ por vías que no suponen de ordinario, ejercicio de autoridad sobre los ciudadanos $^{46} 47$.

43 Vide Carlos GARCÍA OVIEDO, Derecho Administrativo, $8^{\underline{a}}$ ed., preparada por Enrique MARTÍNEZ USEROS, Patronato de Cultura de la Exma Diputación de Murcia, Murcia, 1962, p. 552, nota 2: «Los franceses llaman "establecimientos públicos" a estas entidades configuradas por la doctrina jurídica sobre la base-idea del "servicio público" y las notas que lo caracterizan.

A consecuencia del desarrollo moderno de la actividad industrial del Estado y en relación con estas empresas se preguntan los autores si los referidos "establecimientos públicos" habrán de continuar exclusivamente adscritos a las exigencias del servicio público en su concepción clásica o si, ampliando su cometido, deberán abarcar también, con las rectificaciones oportunas, las actividades propias de las nuevas empresas. En vista de este problema, ciertos autores hablan de "crisis" de la noción de establecimiento público, estimándola estrecha e inadecuada en relación con el momento industrial presente».

44 Vide Gaspar ARIÑO ORTIZ, "Sobre el concepto y significado institucional de la expresión «establecimiento público»”, Documentación Administrativa, 155, (1973), pp. 13-16.

45 Vide Franck MODERNE, "Los entes administrativos instrumentales en Francia" en AAVV, Ad ministración instrumental (Libro homenaje a Manuel Francisco CLAVERO ARÉVALO), Instituto García Oviedo-Cívitas, Madrid, 1994, p. 1747 (el autor de este artículo es Catedrático de Derecho Público en La Sorbona, París): «No existe la expresión "entes administrativos instrumentales" en el Derecho administrativo francés. Pero sí existe la categoría de personas jurídicas administrativas no territoriales, cuya figura más conocida es la de los establecimientos públicos.

Pese a la cantidad enorme de estudios de todos los tipos, de tesis doctorales, de libros, etc., la situación sigue siendo lamentablemente confusa tanto desde el punto de vista del Derecho positivo como desde el punto de vista del análisis jurídico de carácter conceptual».

${ }^{46}$ Vide: Francisco J. JIMÉNEZ de CISNEROS CID, Los organismos autónomos en el derecho público español: tipología y régimen jurídico, Instituto Nacional de Administración Pública, Madrid, 1987, pp. 24-25; Gaspar ARIÑO ORTIZ, "Sobre el concepto y significado institucional de la expresión «establecimiento público»”, Documentación Administrativa, 155, (1973), p. 16. En las pp. 17-18, afirma: «La presencia de elementos sociales, de fuerzas ajenas al Estado-organización, y un principio de orden financiero, aconsejarán dotar de autonomía e independencia a estos entes, sin identificarlos subjetivamente con la Administración centralizada, depositaria general de la puissance publique. Para ello se les reconocerá personalidad jurídica, lo cual les permite constituir su propio patrimonio recibir donaciones o legados, adquirir o enajenar, estar en juicio y asumir sus propias obligaciones. Es ésta -la autonomía e independencia patrimonial y financiera- una nota esencial a la construcción jurídica de estos entes. Por lo mismo, sólo participan en los privilegios e inmunidades propios de la Administración en la medida en que la ley les haya revestido de ellos, debiendo tal atribución ser interpretada con un criterio restrictivo, estricto, referido únicamente al fin que se les ha confiado. La autoridad, la puissance, pertenece únicamente a la Administración central; estos entes no están 
revestidos, propiamente hablando, de poder público, [...]. A ellos se confía la realización de puros actos de gestión, si bien en algunos casos gozan de ciertos privilegios e imponen determinadas cargas (o mejor contribuyen a su ejecución), porque en su actividad "toman parte en la administra ción pública”. Queda, pues, claro que su calificación como Administración queda referida fundamentalmente a la naturaleza de su actividad».

${ }^{47}$ Vide Franck MODERNE, "Los entes administrativos instrumentales en Francia" en AAVV, Ad ministración instrumental (Libro homenaje a Manuel Francisco CLAVERO ARÉVALO), Instituto García Oviedo-Cívitas, Madrid, 1994, pp. 1749-1750: «La aparición y multiplicación en Francia de entes instrumentales del Estado y, en un grado menor, de las corporaciones locales (municipios, departamento, región) se han basado en la técnica jurídicamente sutil y útil de la personalidad moral o personalidad jurídica. Fue el grado extremo de esa organización de forma que cada ente se independice no sólo como simple conjunto de personas físicas y de medios materiales para cumplir una función determinada, sino como centro de imputación de relaciones jurídicas, como personalidad separada de la de la Administración matriz. [...].

Así ha aparecido en el Derecho administrativo francés la fundamental figura del establecimiento público, cuya aplicación más frecuente se dio en el campo de la gestión de servicios administrativos clásicos, los de carácter benéfico, sanitario, docente o cultural (hospitales, hospicios, colegios, liceos, universidades, museos, bibliotecas públicas, etc.). La singularidad bien conocida de esta forma organizativa es la de conciliar la subordinación (relativa) a la autoridad central (concretamente a un departamento ministerial) o local con una autonomía (igualmente relativa) en la gestión de un servicio público clásico.

Se reconoce al establecimiento público una autonomía patrimonial auténtica con el fin de atraer a su patrimonio ciertas liberalidades (herencias, legados, donaciones) y puede servir de marco orgánico aceptable de colaboración en tareas de interés público entre la Administración y los grupos sociales interesados.

La doctrina administrativista francesa no ha prestado excesiva atención a este fenómeno muy pragmático que no necesitaba una particular reflexión teórica. HARIOU si había propuesto una descentralización por organismos autónomos, pero por razones políticas sorprendentes, para ponerlos al abrigo de las maniobra socialistas [...].

La configuración y regulación de estos entes quedaba remitida a sus estatutos respectivos, en los cuales se consignaban de manera más o menos detallada excepciones a veces significativas al sistema administrativo general.

Cabe ahora destacar los rasgos más característicos de la problemática contemporánea de nuestros establecimientos públicos, única forma de entes administrativos instrumentales admitida en el panorama del Derecho administrativo francés. Los entes que, en España, tienen la denominación de "sociedades públicas", de sociedades mercantiles estatales, no serían considerados en Francia como instrumentos de la Administración institucional. Tampoco los organismos de la seguridad social, constituidos como personas de Derecho privado (concretamente sociedades mutualistas). Para la calificación de entes instrumentales administrativos, el criterio orgánico es deliberadamente privilegiado».

Y en la p. 1756 concluye: «Cada año nacen nuevos establecimientos públicos con sus estatutos particulares, sus diferencias formales, su autonomía singular. Pocos son los que desaparecen.

Se dice del Derecho francés que se caracteriza por sus preocupaciones de lógica y de rigor metodológico. La situación de la Administración instrumental demuestra que, al menos en este sector, no hay ni lógica, ni rigor, ni siquiera método». 
En resumen, el concepto unitario de establecimiento público clásico que es el que se recibe en España para calificar a las Cámaras de Comercio se inserta en un concepto de Administración como actividad ${ }^{48}$.

En Alemania, cuando Otto Mayer en 1895 definió lo que era estableci miento público, como "un conjunto de medios materiales y personales que, en manos de un sujeto de la Administración pública, están destinados a servir de manera permanente a un interés público determinado", estudiando esta institución en la parte especial de la asignatura que se dividía en dos secciones, policía de un lado y servicios y establecimientos por otro, la materia administrativa quedaba ordenada y orientada a detectar funciones y estructuras administrativas $^{49}$.

Forsthoff, tras una referencia a las personas jurídicas de Derecho público y un estudio general de las Corporaciones públicas, se centra en los establecimientos públicos. Estas unidades administrativas pueden tener o no capacidad jurídica. Lo decisivo para crear un establecimiento con capacidad jurídica es el deseo de separar determinado sector o complejo administrativo del

48 Vide Gaspar ARIÑO ORTIZ, "Sobre el concepto y significado institucional de la expresión «establecimiento público»”, Documentación Administrativa, 155, (1973), p. 18. En las pp. 19-21, determina las notas definidoras de la figura después de la evolución:

«1. Personalidad jurídico-pública y patrimonio propio distinto del Estado.

2. Su carácter finalista y no territorial.

3. La creación por ley y la atribución por ésta de competencia exclusiva sobre el servicio y de una cierta dosis de imperium (una lista tasada de facultades y privilegios).

4. La independencia (mayor o menor) de su actuación respecto de la Administración central, en lo que pudiéramos llamar actos de ordinaria administración; [...].

5 . El carácter de ente integrador de fuerzas sociales para la realización de determinadas finalidades que requieren una competencia técnica y una dedicación especial; sus órganos de gobierno están compuestos de ordinario por representantes de la Administración y de la sociedad. Esta representación social es de distinto grado: en los entes corporativos es una representación natural; en los fundacionales será una representación buscada y nunca verdaderamente conseguida.

6. La existencia de una relación de tutela con el Estado, tanto más intensa cuanto mayor sea la dependencia financiera de éste, y que en todo caso alcanza a los actos graves de disposición sobre sus bienes (enajenación, hipotecas y cargas reales, empréstitos) y a la aprobación de su presupuesto».

49 Vide Alfredo GALLEGO ANABITARTE, "De los establecimientos públicos y otras personas jurídico públicas en España”, estudio preliminar, en Francisco J. JIMÉNEZ de CISNEROS CID, Los organismos autónomos en el derecho público español: tipología y régimen jurídico, Instituto Nacional de Administración Pública, Madrid, 1987, p. XV. En las pp. XXI-XXIV explica la confusión doctrinal en el derecho español sobre el concepto de establecimiento y lo compara con el derecho alemán de la época. 
resto de las funciones del "Organismo madre". Los dos tipos fundamentales de establecimientos públicos son: aquellos que surgen primariamente por necesidad de especialización; los establecimientos de uso o utilización ${ }^{50} 51$.

\subsubsection{La importación de la categoría de los "establecimientos públicos" en el derecho es - pañol}

Con anterioridad a 1901, el concepto en nuestra legislación es mucho más estricto y estatalizado que en Francia ${ }^{52}$. Hasta esa fecha, no se comprendieron nunca como tales los entes representativos de intereses. Nuestros establecimientos públicos fueron puras dependencias gubernativas que desarro-

\footnotetext{
50 Vide Francisco J. JIMÉNEZ de CISNEROS CID, Los organismos autónomos en el derecho público español: tipología y régimen jurídico, Instituto Nacional de Administración Pública, Madrid, 1987, p. 17: «Si bien los primeros siguen los principios generales de la Administración pública, los segundos presentan más problemas dado que la relación jurídica de utilización puede ser pública o privada, como ya se vio anteriormente en la clasificación de Wolff.

Uno de los puntos más importantes de la obra de Forsthoff es haber tratado de distinguir los establecimientos públicos con utilización jurídico-privada de las empresas industriales o comerciales que también actúan en forma jurídico-privada: ya se sabe que el criterio aquí clave es el de la Administración de asistencia vital (Daseinsvorsorge), ya que donde existe este tipo de prestación (abastecimiento de agua, gas, etc.), aunque la relación sea jurídico-privada, estamos ante Administración pública material; estaríamos pues ante una función administrativa a la que es obligado someter a unas ligaduras de Derecho público (por ejemplo, respecto a los derechos fundamentales para evitar discriminaciones, violación del principio de igualdad, etc.).

Se comprende pues que junto a la penetración analítica en el fenómeno organizativo que supone el establecimiento público, otra cuestión importante que plantean estas organizaciones es la necesidad de distinguir entre el régimen jurídico público y privado. El análisis de Forsthoff pone un peso evidente en evitar "la huida en el Derecho privado" de la Administración pública, cuando está ejerciendo verdaderas funciones administrativas, y no simplemente actividades privadas de
} lucro o ganancia».

${ }^{51}$ Ibídem, pp. 18-19: «En la reunión de profesores alemanes de derecho público en 1985, se trató monográficamente el establecimiento público mediante ponencias que distinguieron entre establecimientos públicos con o sin personalidad jurídica, o a través de otro enfoque que los configura como una unidad administrativa autónoma con múltiples opciones según la técnica jurídico-orgánica que se utilice».

52 Vide José Luis PIÑAR MAÑAS y Alicia REAL PÉREZ, Legislación sobre instituciones de beneficen cia particular, Ministerio de Trabajo y Seguridad Social, Madrid, 1987, p. 30: «Las prestaciones se llevan a cabo por medio de los llamados Establecimientos de Beneficencia, que son órganos administrativos (carentes en principio, de personalidad jurídica diferenciada) creados específicamente para cumplir esta misión. Los Establecimientos de Beneficencia son órganos de la Administración del Estado (Establecimientos generales), de las provincias (Establecimientos provinciales) o de los municipios (Establecimientos municipales), en concordancia con los tres escalones 
llaron actividad estatal, en un régimen organizativo y financiero más o menos integrado en el Estado, y sin que detrás de ellas hubiese casi nunca intereses profesionales y sociales. Ariño Ortiz lo ha explicado, magistralmente, asín ${ }^{53}$ :

«En efecto, durante toda la primera mitad del siglo XIX fueron perfectamente reconocidas como personas jurídicas distintas a los "establecimientos" (estatales) las asociaciones gremiales, las fundaciones benéficas privadas y las corporaciones económicas o profesionales [así en el proyecto de García Goyena de 1851, arts. 33 y 608 ("los cuerpos y asociaciones que se comprenden bajo la denominación de manos muertas") ], quedando solamente sometidas a la inspección del Gobierno (art. 17 de la ley de 28 de enero de 1848). Los principios de 1868 no harán sino insistir en esta misma línea. Y esta misma diferencia entre corporaciones y establecimientos públicos se recogerá en el Código Civil, en los artículos 35, 748 y 994, aun cuando unas y otras se consideren, naturalmente personas pú blicas, distintas a las de interés público (que no prejuzgan tal publicidad): en efecto, como ha escrito García Trevijano: "el Código Civil habla de los establecimientos públicos en los artículos 748 y 994 en un sentido restringido, entendiendo por tales aquellas personas jurídico-públicas de tipo fundacional y caracterizadas por la reunión de un conjunto de elementos

mencionados en que se desarrolla la actividad de beneficencia. El reparto de competencias prestacionales se realiza del siguiente modo: corresponden a la Administración del Estado (Establecimientos generales), las necesidades permanentes y las que requieren una atención especial; a las provincias (Establecimientos provinciales), las enfermedades comunes, el auxilio a menesterosos incapaces de un trabajo personal y el amparo y la educación de menores desasistidos; a los municipios (Establecimientos municipales), las enfermedades accidentales, la conducción de los necesitados a los Establecimientos generales y provinciales y la asistencia domiciliaria» (arts. 1 y ss. del Reglamento de 1852). Vide Miguel NAVAJAS REBOLLAR, La nueva Administración instrumental, Colex, Madrid, 2000, pp. 30-36. Vide Elena MAZA ZORRILLA, Pobreza y asistencia social en España, o.c., p. 176: «A la reestructuración política proyectada por las Cortes de Cádiz se asocia un plan asistencial y sanitario acorde con el pensamiento liberal. La Constitución de 1812 reclama para el Estado y los organismos públicos (artículo 321) la asunción y el control de la asistencia social.

Establece que serán los Ayuntamientos lo encargados de cuidar y supervisar los Hospitales, Hospicios, Casas de Expósitos y demás establecimientos benéficos costeados por el común, "bajo las reglas que se prescriban". Los centros asistenciales de patronato particular se regirán por sus Estatutos, si bien, sujetos a la inspección de los Jefes políticos provinciales a fin de evitar abusos e irregularidades. El artículo 335 confía a las Diputaciones provinciales la responsabilidad de que "los establecimientos piadosos y de beneficencia llenen su respectivo objeto, proponiendo al Gobierno las reglas que estimen conducentes para la reforma de los abusos que observaren».

53 Vide Gaspar ARIÑO ORTIZ, "Sobre el concepto y significado institucional de la expresión «establecimiento público»", Documentación Administrativa, 155, (1973), p. 23, nota 48. 
materiales y personales destinados a fines benéficos y culturales fundamentalmente, que eran los únicos existentes en el momento de la promulgación de dicho Cuerpo Legal, no pudiendo, por tanto, ampliarse dichos preceptos a las demás entidades de base corporativa", [...]. Concluyendo: no teníamos por qué haber sufrido la confusión que tal calificación unitaria encerraba (era meter en un mismo cajón seres muy diferentes). Pero puestos a importar, importamos también las confusiones».

A partir de 1901, el concepto de establecimientos público sufrirá en España un proceso de dilatación similar al de Francia, aunque nunca llegó a alcanzar tanta intensidad ${ }^{54}$.

En resumen, esta ampliación del concepto de establecimiento público, producida sobre todo en la doctrina francesa del servicio público, sembró la confusión también entre la doctrina española, que trató de extender el concepto a otros dos grupos de entes (además de los originariamente cubiertos por él $)^{55}: 1$. A entes de base asociativa para la gestión y defensa de intereses de

54 Vide Elena MAZA ZORRILLA, Pobreza y asistencia social en España, o.c., p. 143: «Numerosos escritos se refieren a las Cajas de Ahorros como los "nuevos establecimientos de previsión, utilidad y beneficencia públicos" [...]». En la p. 145 afirma: «[...]. Su clasificación como "establecimientos municipales de beneficencia" las sitúa dentro de la vigente ley del sector del 20 de junio de 1849 . Con todo, a pesar de tan detallada normativa, no se conseguirá la pretendida uniformidad porque, al margen del ordenamiento legal, gran parte de las Cajas y Montes seguirán funcionando según sus propios Estatutos y Reglamentos, preceptivamente aprobados por el gobierno». Vide: Fernando GARRIDO FALLA, "La Administración institucional", en la obra colectiva La España de los años 70, Vol. III-2, Madrid, 1974, pp. 65-67; Fernando GARRIDO FALLA, "Origen y evolución de las entidades instrumentales de las Administraciones públicas”, en AAVV, Administración ins trumental (Libro homenaje a Manuel Francisco Clavero Arévalo), Cívitas, Madrid, 1994, pp. 35-36.

55 Vide Mariano BAENA del ALCÁZAR, "Los entes funcionalmente descentralizados y su relación con la Administración central”, $R A P, 44,(1964)$, pp. 73-75: «[...]. Hoy día (se está refiriendo a los establecimientos públicos) no puede mantenerse en modo alguno esta categoría conceptual como aplicable a todas las personas jurídicas no territoriales.

La noción clásica de establecimiento público se ha intentado mantener por ONNOIS, para quien es erróneo considerar que el establecimiento público tiene un régimen determinado y único, debiendo caracterizarse por la concurrencia de las notas de organismo público, personalidad moral y vocación especial. De todas formas lo evidente es que la vieja noción ha sufrido un proceso de crisis universalmente reconocido.

Según RIVERO las dificultades existentes en torno al establecimiento público se agravarían considerablemente entre las dos guerras con el desenvolvimiento de los establecimientos públicos industriales y comerciales, expresión que tiene un origen jurisprudencial, y que fue empleada por primera vez en un texto legal en el Decreto de 15 de diciembre de 1934. Los nuevos entes escapaban, desde luego, a las normas tradicionales. [...]. 
grupos, a los que se da un reconocimiento público y se les inviste de potestad, a ciertos efectos: cámaras, colegios, etc. 2. A ciertas empresas creadas ad hoc para la gestión de determinados servicios públicos de naturaleza fiscal, industrial o comercial: algunos monopolios fiscales, líneas férreas estatales, establecimientos nacionales de gas o electricidad, etc.

Con lo cual, en definitiva, venía a abarcar tal concepto -aquí, como en Francia- a todas las entidades o personas jurídico-públicas no territoriales, distintas de la Administración Central del Estado ${ }^{56}$. Otros pronunciamientos doctrinales sostienen que se puede afirmar sin reparo, que los establecimientos públicos no forman una clase especial de personas jurídico-públicas, sino que se disuelven en el concepto de Institución pública o Fundación pública; en cualquier caso responden a los criterios definitorios de las personas de base fundacional, por lo que deben estudiarse dentro de estas figuras, sin independencia propia ${ }^{57}$.

Escribía el profesor Nieto las siguientes palabras:

«En la corta y agitada historia del derecho administrativo los establecimientos públicos nos ofrecen el ejemplo verdaderamente extraordinario, de una figura que en el breve espacio de una centuria ha experimentado una evolución completa: nace, se desarrolla, llega a su apogeo, entra en crisis, decae y hasta desaparece sin dejar rastro -o, por lo menos, se transforma enteramente- e incluso muestra atisbos de una regeneración ${ }^{58}$.

De aquí se siguió, como no podía menos de suceder, una verdadera descomposición de la noción de establecimiento público, tanto más explicable cuanto que el concepto de establecimiento intervencionista presenta unas fronteras bastante imprecisas. De este modo pudo afirmarse que la introducción de elementos muy extraños había hecho perder a la noción de establecimiento público la claridad y la simplicidad que había adquirido en el Derecho administrativo francés hasta el extremo de que se ha dicho por algún autor que al referirse al establecimiento público se está hablando de una noción genérica y no específica».

56 Vide Gaspar ARIÑO ORTIZ, "Sobre el concepto y significado institucional de la expresión «establecimiento público»”, Documentación Administrativa, 155, (1973), pp. 24-25. En las pp. $26-27$ plantea ¿cómo entender hoy la calificación de establecimiento público a la vista de nuestro ordenamiento? y contesta: «En definitiva, se trata siempre de entes personificados integrados en la Administración del Estado, provincia o municipio».

57 Vide. Francisco J. JIMÉNEZ de CISNEROS CID, Los organismos autónomos en el derecho público es pañol: tipología y régimen jurídico, Instituto Nacional de Administración Pública, Madrid, 1987, p. 71.

58 Vide Alejandro NIETO GARCÍA, "Valor actual de los establecimientos públicos" en Estudios homenaje a Sayagués Laso, Tomo IV, 1959, p. 1053. 
Lo cierto es que Nieto estudia y diferencia varias etapas. Una primera fase de formación empírica del concepto. En estos primeros momentos, establecimiento vale tanto como "unidad organizativa", en lo que se apunta, ciertamente, un germen de lo que andando los años se denominarán personas jurídicas, que por entonces no han surgido aún en el horizonte administrativo ${ }^{59}$. Una segunda fase de categorización del concepto. Una tercera fase donde el concepto entra en crisis, y en España serán las formulaciones de los profesores Garrido Falla -quien tuvo el acierto de distinguir el Establecimiento Público de los otros entes que realizan una descentralización funcional en sentido estricto- y García Trevijano, las que ponen de manifiesto los elementos claves de la situación a la que se ha llegado. En el año 1969 se atisba una posible rehabilitación y los tres rasgos definitivos que se pueden formular de la siguiente manera: se trata de personas jurídicas de Derecho Público; tienen una finalidad especial; no tienen base corporativa. En este sentido el profesor Nieto señala que los establecimientos públicos podrían valer para dar unidad dogmática a todas las variedades de personas jurídicas públicas no territoriales y no corporativas ${ }^{60} 61$.

\subsubsection{Las rifas como medio de financiación de los establecimientos de beneficencia}

El Estado ilustrado de finales del siglo XVIII, embarcado en una política de planificación y racionalización de la caridad, introdujo la lotería como medio de financiación de los establecimientos de beneficencia. Desde entonces la relación entre el juego y la beneficencia es una constante de la política asistencial de este país.

\footnotetext{
${ }^{59}$ Ibídem, p. 1054.

${ }^{60}$ Ibídem, pp. 1071-1072.

61 Vide Alfredo GALLEGO ANABITARTE, "De los establecimientos públicos y otras personas jurídico públicas en España”, estudio preliminar, en Francisco J. JIMÉNEZ de CISNEROS CID, Los organismos autónomos en el derecho público español: tipología y régimen jurídico, Instituto Nacional de Administración Pública, Madrid, 1987, pp. XXXVIII-XXXIX: «[...]. Como hipótesis: el estableci miento público es una unidad orgánica -personificada o no- que dotada de unos medios personales, materia les y técnicos específicos, ofrecen una serie de prestaciones a los particulares para la satisfacción de un fin pú blico determinado. Establecimiento público es la Biblioteca Nacional, Hospitales, Facultades Universitarias, Cementerios, Institutos de Enseñanza Media, Piscinas Municipales o Públicas, etc., y tantas otras unidades administrativas que la doctrina por el hecho de no estar personificadas, ni estudia, ni analiza, y conformándose con denominarlas Organos. [...].

Este concepto de establecimiento público sería un concepto funcional, que atraviesa toda la Administración Pública, esté o no personificado. Permite indudablemente una superior penetración
} analítica y clasificatoria en la organización administrativa». 
Durante el siglo XIX el Estado concedió a algunos centros de beneficencia el privilegio de explotar loterías particulares, o rifas, que pronto se convirtieron en la principal fuente de recursos de estos establecimientos. La política de concesiones especiales finalizó con la Ley del 31 de diciembre de 1887, una vez que la competencia de las rifas legalizadas, además de las clandestinas, comenzaron a reducir sensiblemente los ingresos de la Lotería Nacional. Sin embargo, las medidas contra las rifas particulares y locales nunca fueron eficaces. El hecho es que, dada la debilidad de las haciendas locales para hacer frente a los gastos de beneficencia, no pocas Diputaciones Provinciales y Ayuntamientos recurrían al juego como fuente de recursos. Así, algunos gobiernos locales toleraban, o incluso promocionaban rifas, o bien, se toleraban las casas de juego a cambio de una contribución ${ }^{62}$.

Sobre los antecedentes del cupón, se señala que en el año 1903, la Junta de Damas de Alicante, organizó, a propuesta de un grupo de ciegos, la primera rifa de boletos numerados, que vendían éstos, simuladamente. Esta rifa obtuvo gran éxito y permitió vivir a los ciegos alicantinos con desahogo. Poco a poco se fue implantando en las provincias del sureste español: en Murcia en 1910, en Cartagena en 1918, en Almería en 1921, etc. ${ }^{63}$.

\subsubsection{El recogimiento de los ciegos en establecimientos de beneficencia y su negativa a ingresar en asilos 64}

Aparte de la creación de colegios, la Sociedad Matritense propuso el recogimiento de los ciegos en asilos y establecimientos de beneficencia. Pero al

\footnotetext{
${ }^{62}$ Vide Roberto GARVIA SOTO, La organización nacional de ciegos. Un estudio institucional, Centro de Estudios Avanzados en Ciencias Sociales, Madrid, 1993, pp. 56-57.

${ }^{63}$ Vide Alberto DAUDÉN TALLAVÍ, Los ciegos como grupo social y su relación con el Estado: 18001938, ONCE, Madrid, 1996, p. 86.

${ }^{64}$ Vide Jesús MONTORO MARTÍNEZ, Sintesis histórica y estructural de la Organización Nacional de Ciegos Españoles, Centro de Recursos Educativos Espíritu Santo, Alicante, 1989, p. 152, donde establece una clasificación de los ciegos según su modo de subsistir a lo largo de la historia, diferenciando los cuatro grupos siguientes:

«a) Los mantenidos por sus parientes o por asilos y otras casas de misericordia hasta el final de sus dias. Muchas familias con bienes de fortuna y posibilidades para cuidar cumplidamente a sus allegados ciegos, los atendían en el hogar, pero cuando se les presentaba la oportunidad de ingresarlos en un hospicio, la aprovechaban sin ningún escrúpulo de conciencia.

En los asilos, los ciegos eran obligados, entre otras cosas, a realizar los trabajos domésticos más desagradables: fregar los platos, lavar la ropa, etc. Comían poco y mal, vestían miserablemente,
} 
igual que en el caso de los colegios esta medida tampoco tuvo éxito. Ni había suficientes asilos para recoger a los ciegos mendigos ${ }^{65}$, ni como era de esperar, los ciegos mendigos querían ser recluidos en asilos u hospicios. En palabras de un líder de una organización de mendigos ${ }^{66}$ :

pasaban frío y con frecuencia salían a postular por las calles con el fin de recaudar fondos para el sostenimiento del hospicio. Continuamente soportaban humillaciones escuchando con machacona insistencia que eran ciegos y que además, se les cuidaba en el asilo por caridad, ya que no tenían otro sitio donde vivir.

b) Los ciegos con buenos recursos económicos. Eran aquellos que nunca tuvieron graves problemas sociales. [...]. Las mujeres ciegas con alguna fortuna que no conseguían casarse, y que tenían miedo a la soledad de la soltería, daban de dote sus bienes a algún convento a cambio de que en él las cuidaran el resto de sus vidas o, las admitiera la comunidad como religiosas [...].

c) Los mendigos o pordioseros. Éstos, se concentraban en los mercados, romerías, santuarios, cruces de importantes caminos y de otros lugares multitudinarios. En las puertas de las casas nobles y de los templos siempre montaban la guardia mendigos ciegos, esperando recibir las migajas del banquete del gran magnate o las monedas de los fieles, que se juntaban en las iglesias.

Desde que en el siglo XI el Papado declarase que la caridad era una virtud teologal, los cristianos se mostraron más generosos.

d) Los ciegos que se ganaban dignamente la vida con su arte e ingenio. Eran quienes preferentemente cultivaban la música, dando lecciones o tocando toda clase de instrumentos en bailes, romerías o templos.

Muchas de estas personas cantaban coplas y romances, narraban crímenes y aventuras amorosas, vendían bálsamos, pomadas y hierbas medicinales para curar todos los males, en definitiva, hacían verdaderos milagros para engañar y no ser engañados».

65 Vide Elena MAZA ZORRILLA, Pobreza y asistencia social en España, siglos XVI al XX, o.c., pp. 111-112: «De la abigarrada producción de Gaspar Melchor de Jovellanos nos interesa de manera especial -publicado en 1778-, su "Discurso acerca de la situación y división interior de los hospicios con respecto a su salubridad". Su originalidad estriba en que, contra lo aceptado habitualmente, subraya la inconveniencia de unos hospicios "adonde se recojan indistintamente todas las clases de pobres, desvalidos, robustos e impedidos de un estado”. Si prevalece la razón sobre la costumbre, ni la salud, ni la higiene, ni la economía, ni la moral permitirán sostener las instalaciones precisas para acoger a semejante "ejército de miserables". Para él, un hospicio general que no entrañe problemas de hacinamiento e insalubridad, es una quimera, pura fantasía.

Muy diferente es su criterio acerca de los hospicios "especializados", en los que cada sección corresponde a un determinado tipo de menesterosos con total separación y tratamiento específico. Según el carácter de tránsito o permanencia, organiza su dedicación peculiar con una finalidad educativa (niños), caritativa (ancianos) o correccional (vagos)».

66 Vide Roberto GARVIA SOTO, La organización nacional de ciegos. Un estudio institucional, Centro de Estudios Avanzados en Ciencias Sociales, Madrid, 1993, p. 36, nota 20: «Verdad es que los individuos de la Cofradía de ciegos (de Madrid) no se conceptuaban mendigos, y hasta tenían como deshonra ser comparados con ellos, por más que viviesen de pedir limosna; pues esta limosna se les daba, según su dicho, en pago de las oraciones que rezaban o cantaban al son de destempladas guitarras, como aún lo verifican en el día (1886), y además, ocupándose de la venta de librotes y papeles, podría conceptuárseles industriales y de profesión conocida». 
"La asilación obligatoria es una pena injusta y cruel de privación de libertad. ¿Se asila a los pobres por su bien o por quitárselos la sociedad brutalmente de en medio?. ¿Es por lo primero?. Entonces, ¿porqué no quieren ser asilados?. ¿Qué especie de asilación es esa que les parece peor que la miseria y el hambre?. [...]. La Constitución del Estado declara que ningún ciudadano puede ser privado de su libertad sino por mandato de juez competente. ¿Es que los ciegos no son ciudadanos?. ¿Es que para ellos no se ha escrito la Constitución?”.

El rechazo de los ciegos a los asilos se muestra en el hecho de que en las estadísticas de asilos para ciegos, muchos de estos centros estuvieran especializados en recoger no a ciegos en condiciones de pedir limosna en las calles ${ }^{67}$, sino a ciegos incapaces de soportar la competencia en el mercado de la caridad; esto es, mujeres, ancianos, y niños ciegos ${ }^{68}$. Por el contrario, los ciegos hábiles para mendigar en las calles se organizaron en auténticas sociedades de resistencia para protegerse contra las campañas de recogida de mendigos ${ }^{69}$. Por lo demás, ni las pensiones, ni la venta de baratijas y décimos de lotería les suponía a los ciegos unos ingresos iguales a los que obtenían mendigando, con lo que, o bien vendían y mendigaban, o sencillamente mendigaban, de tal

\footnotetext{
67 Vide, JUNTA GENERAL DE ESTADÍSTICA, Anuario Estadístico de España 1860-1861, p. 88, donde se determina según datos estadísticos elaborados en 1860, que el número total de ciegos pobres en España, exceptuando Santander, es de 17.379.

68 Vide Roberto GARVIA SOTO, La organización nacional de ciegos. Un estudio institucional, Centro de Estudios Avanzados en Ciencias Sociales, Madrid, 1993, p. 38, nota 24: «Según los Nuevos Apuntes, el Hospital del Rey (establecimiento de Beneficencia General) admitía a ciegos mayores de 40 años. El Asilo Amparo de Santa Lucía, recogía a ciegos mayores de 50 años. El Asilo de San José de Madrid admitía a niñas ciegas. Recogían niños y niñas ciegos el Hospicio de Nuestra Señora de la Misericordia de Valencia, el hospital de San Rafael de Barcelona, la Casa de Caridad de Barcelona, y el Asilo San Juan de Dios de Barcelona. El Asilo del Patriarca San Joaquín de Madrid estaba especializado en mujeres ciegas. Además de en los Nuevos Apuntes, hay estadísticas de asilos para sordomudos y ciegos en Sandino Agudo (1922), y en las realizadas por la Dirección General de Administración sobre beneficencia particular de los años 1922, 1926 y 1930 (Estadísticas de Beneficencia). El Anuario de 1915 mantiene que ya existían 14 asilos para ciegos y sordomudos, sin especificar dónde se encontraban, y si eran establecimientos especiales para ciegos o sordomudos o asilos donde había una sección especial para estos dos colectivos. Tampoco especifica si son establecimientos públicos de beneficencia o establecimientos privados, o si son escuelas o sólo asilos. Los Nuevos Apuntes de 1919 ofrecen las estadísticas más detalladas. La estadística de Sandino Agudo (1922) mantiene que en las Casas de Misericordia y Hospicios de 8 provincias hay departamentos especiales para ciegos, pero sólo en 5 hay departamentos para sordomudos».
}

${ }^{69}$ Ibídem, pp. 38-39. 
forma que hacían inútiles los afanes del Patronato de retirarles de la mendici$\operatorname{dad}^{70}$.

\section{Educación: una herramienta fundamental para el avance social de los invi-} dentes.

\subsection{El paso de la prehistoria a la historia para los ciegos.}

En los últimos años del siglo XVIII y los primeros del XIX en el período de tiempo que media entre 1771 y 1829 , tienen lugar dos acontecimientos de tal trascendencia, que van a abrir una nueva era en la historia de los ciegos. Dos franceses Valentín Haüy y Louis Braille, son los protagonistas de este hecho. Valentín Haüy es el inventor del primer alfabeto que hace posible la lectura a los ciegos. Louis Braille inventa el sistema utilizado todavía hoy por los carentes de vista.

El paso de la prehistoria a la historia se da cuando la humanidad inventa la escritura. Lo mismo podemos decir de los ciegos. Hasta Valentín Haüy, los ciegos vivían en prehistoria larga y triste, pues los videntes hacía muchos años que habían traspasado el umbral de la historia ${ }^{71}$.

\subsection{La creación de colegios para ciegos.}

Con anterioridad a la obra de Valentín Haüy, se crea en Sevilla la Fundación Hospital-Colegio para Ciegos Pozosanto, creado por las Hermanas Terciarias de San Francisco, en el año $1666^{72}$.

Desde que, en 1810, el humilde relojero catalán Ricart pone en España la primera piedra para la enseñanza de ciegos, «la beneficencia, para aplicarse a

\footnotetext{
${ }^{70}$ Ibídem, p. 47, nota 33: «A las preguntas de un periodista sobre si seguía siendo necesario mendigar tras las medidas del Patronato de Madrid, respondía una mujer ciega que "Si, porque aunque algunas tenemos como usted ve, la autorización para vender participaciones de lotería, lo que produce esto es tan escaso, una peseta o seis reales al día, que más bien resulta un pretexto para mendigar [...]. Lo de los oficios [...] es una superchería más. Somos unos ochocientos ciegos en este género de vida. Sólo cuarenta tienen ocupación de cesteros !Y ganan medio duro" (La Voz, 12 de septiembre de 1922)».

71 Vide Enrique PAJON MECLOY, Psicología de la ceguera, Editorial Fragua, Madrid, 1974, p. 19.

72 Vide C. BUENO, La promoción personal de los ciegos y su dignidad humana, Tiflos, Barcelona, 1966 , p. 47.
} 
estos desgraciados, tomo un rumbo más certero, y se crean multitud de colegios en el extranjero y en España» ${ }^{73}$.

En el número 11 de la madrileña calle del Turco, ya existía desde principios de siglo, una escuela de sordomudos patrocinada y sostenida por la Sociedad Económica Matritense de Amigos del País, organización que cedió a Juan Manuel Ballesteros, profesor y luego director del centro docente, una sala del edificio para que fundase allí, el 20 de febrero de 1842, la primera Escuela de Ciegos que hubo en la capital de España, y que en un principio, también estuvo protegida y financiada por la Sociedad Económica Matritense de Amigos del País. Por Real Orden del 26 de enero de 1852, se declaraba al Real Colegio Nacional de Sordomudos y de Ciegos establecimiento de Instrucción Pública, pasando a depender del Ministerio de Fomento ${ }^{74}$.

La Ley de Instrucción de 1857 (conocida como Ley Moyano) dio un nuevo impulso a los colegios de sordomudos y ciegos. En su artículo 108 se dis-

73 Vide F. MATA ISLA, El problema social de la ceguera en España y treinta años de la ONCE: 19381968, La Línea de la Concepción, Cádiz, 1969, p. 165. Sin embargo se da también como fecha la del 1 de mayo de 1820, Vide Alberto DAUDEN TALLAVÍ, Los ciegos como grupo social y su relación con el Estado: 1800-1938, o.c, p. 54. Vide Pierre HENRI, La vida y la obra de Luís Braille, traducción de Julio Osuna, ONCE, Madrid, 1988, p. 28, donde relata las lamentables condiciones de la escuela de ciegos de París: «[...]. Para describir lo incómodo e insalubre de aquello era, habría que citar in extenso los informes que los médicos de consulta emitieron el 8 de mayo de 1821 y el 4 de diciembre de 1828. En ambos se declara que "la casa está emplazada en un barrio bajo, mal aireado y sujeto a muchas emanaciones más o menos infectas". En el primero dicen: "Lo que más nos ha chocado en el aspecto de aquellos infortunados chicos es su tez lívida y su apariencia caquéctica. Muchos tienen predisposición manifiesta a la escrófula, y algunos, hasta ganglios inflamados". Uno tiembla al pensar que Braille pudiera ser uno de éstos.

Para completar el cuadro, habría que sacar también del Moniteur parte del informe presentado en la sesión de la Cámara de 29 de febrero de 1832. En la memoria que la Comisión discutió aquel día se lee textualmente: "La casa ocupada por la Institución de jóvenes ciegos es muy malsana, y el índice de mortalidad que se da entre los alumnos, muy alto". Y: "Ciertamente los chicos ciegos mueren en la casa que les ha sido designada y su existencia está en gran peligro".

Habría también que reproducir íntegra la intervención del diputado Meilheurat en la sesión del 14 de mayo de 1838. [...].

"SEÑORES. Ayer he ido a visitar el establecimiento de Jóvenes Ciegos y puedo aseguraros que no hay la menor exageración en la descripción [...], no hay descripción que pueda daros idea de aquel local estrecho, infecto y tenebroso; de aquellos pasillos partidos en dos para hacer verdaderos cuchitriles que allí llaman talleres o clases; de aquellas innumerables escaleras tortuosas y carcomidas que lejos de estar preparadas para desgraciados que sólo pueden guiarse por el tacto, parecen -permitidme la expresión- un reto lanzado a la ceguera de aquellos niños. [...]”».

74 Vide Alberto DAUDEN TALLAVÍ, Los ciegos como grupo social y su relación con el Estado: 18001938, o.c., pp. 54-55. 
ponía que, a iniciativa de los rectores, se crearían escuelas especiales, subvencionadas por las diputaciones de cada distrito universitario. a falta de plazas, los niños ciegos y sordos deberían ser escolarizados en escuelas comunes ${ }^{75}$. Algunas universidades cumplieron estas disposiciones ${ }^{76} 77$. Así se creó en 1863 un colegio en Salamanca. Al siguiente año se crearon dos nuevos colegios, uno en Santiago y el otro en Burgos.

75 Vide Roberto GARVIA SOTO, La organización nacional de ciegos. Un estudio institucional, o.c., pp. 47-48: «Si bien aparentemente los problemas de los sordomudos y de los ciegos eran semejantes, fracasos de este tipo pronto mostraron que ambos problemas eran de naturaleza bien distinta. $[\ldots]$.

"En efecto, mientras el sordomudo previamente educado puede ejercer con provecho la mayor parte de las profesiones que constituyen la actividad humana [...], el ciego, por el contrario halla muy restringido su campo de trabajo, ya que la casi totalidad de sus ocupaciones, y sobre todo las de carácter manual, requieren imprescindiblemente el ejercicio de la vista. Fuera de las profesiones literarias o musicales (no siempre asequibles a los ciegos pobres), la tipografía en relieve y un corto número de oficios de manipulación grosera, como la cordelería, la cepillería, los tejidos de fibras vegetales, y pocos más, el ciego tiene cerrado el campo de trabajo y por eso cae, con dolorosa frecuencia, en la mendicidad callejera, para la que, en el estado actual de nuestros organismos sociales, hay que tener una tolerancia misericordiosa. Por eso, mientras que el problema de los sordomudos es todo de carácter pedagógico, el de los ciegos tiene substancialmente carácter social'».

76 Vide Enrique PAJON MECLOY, Psicología de la ceguera, o.c., p. 29: «En 1863 se fundó el primer colegio de ciegos de España, situado en Alicante y que, a través de múltiples cambios de forma, localización y propiedad, sigue abierto actualmente. Poco después se fundó el colegio Nacional de Ciegos en Chamartín de la Roda, regido en nuestros días, al igual que el de Alicante, por la ONCE. Otras instituciones educativas fueron apareciendo sucesivamente en distintos puntos del área nacional pero de efímera duración. Por otra parte, la capacidad total de estos centros resultaba muy insuficiente para atender todas las necesidades. Mucho menos se había resuelto el problema laboral, quedando reducidos los casos de ciegos colocados a unos pocos que ejercían como maestros en los propios colegios de ciegos. La situación real de la inmensa mayoría era la de la mendicidad callejera como único recurso. El hecho quedó resaltado cuando el 25 de septiembre de 1935, mientras tenía lugar una sesión de la asamblea que por aquellos días celebró en Madrid la Federación Hispánica de Ciegos, en los locales del Ateneo Teosófico, calle del Factor, 5 , unos ciegos irrumpieron en la sala pidiendo el derecho a la libre mendicidad».

77 Vide Alberto DAUDÉN TALLAVÍ, Los ciegos como grupo social y su relación con el Estado: 18001938, o.c., pp. 167-168, donde reproduce como documento $\mathrm{n}^{\circ} 1$ en el apéndice documental, las instrucciones dadas a Francisco Fernández Villabrille para su visita a colegios de Francia y Bélgica, dada en Madrid a 19 de julio de 1858:

«Dirección general de Instrucción pública.

Negociado [...].

Instrucciones para la visita de los colegios de sordo-mudos y ciegos de Francia y Bélgica que ha de practicar Don Francisco Fernández Villabrille.

1 a. Serán objeto principal de estudio en la visita de cada uno de los colegios los puntos siguientes: 
Sin embargo, los resultados son muy pobres. Según datos recogidos por la propia $\mathrm{ONCE}^{78}$, las instituciones tiflológicas importantes a principios del siglo XX, eran las siguientes:

Disposición del local.

Régimen de disciplina y sistema de premios y castigos.

Distribución del tiempo y el trabajo.

Ejercicios corporales y aparatos gimnásticos.

Prácticas religiosas y medios de educación moral.

Programa general de enseñanza y duración y distribución de los estudios.

Programa especial, métodos, prácticas y procedimientos, libros y medios materiales de cada ramo de enseñanza.

Número de profesores y auxiliares y el de alumnos de cada clase.

Ramos que comprende la enseñanza industrial y extensión que se da a cada una, indicando los ejercicios que se practican y su resultado.

Diferencia entre el régimen y disciplina de las clases de niños y los de las niñas.

$2^{o}$. En la visita se recogerán los planos de los edificios, los reglamentos, los programas y otros documentos de fácil adquisición y se tomará nota de los aparatos y medios materiales de enseñanza, haciendo una sucinta descripción de los que no sean conocidos en el Colegio de Madrid.

$3^{\circ}$. Luego de llegar a París el Comisionado se presentará en la legación española con objeto de que se le faciliten las noticias convenientes para la visita de los colegios de la Capital.

$4^{\circ}$. Tan pronto como le sea posible, comunicará a la Dirección General de Instrucción Pública las noticias que adquiera acerca de los Colegios de Francia y Bélgica cuya visita sea más conducente al cumplimiento de su encargo.

$5^{\circ}$. Después de practicar la visita de los colegios de París pasará a los puntos que determine el Gobierno con el propio objeto.

$6^{\circ}$. Dará parte mensualmente a la Dirección General de Instrucción Pública de los trabajos en que se hubiere [...].

$7^{\circ}$. Terminada la visita y de vuelta en Madrid, se presentará a la Dirección General de Instrucción Pública una memoria circunstanciada que exprese el estado de cada uno de los establecimientos, la cual deberá [...] los puntos indicados en la instrucción primera y demás que considere conveniente, proponiendo por sí misma las mejoras que en vista de lo que haya observado juzgue útiles y practicables en el colegio de Madrid, así como la adquisición de los aparatos y medios de enseñanza que produzcan mejores resultados.

$8^{\circ}$. A la memoria deberán acompañar los planos, reglamentos, programas, libros y demás documentos que haya reunido.

Madrid, 19 de julio de 1858.

Es copia.

Mํápez».

78 Vide ONCE, 65 años de historia, ONCE, Madrid, 2004, p. 16. 
DOCUMERTOS

\begin{tabular}{|c|c|}
\hline Provincia & Instituciones \\
\hline Alicante: Alicante. & $\begin{array}{l}\text { Asociación "La Piedad". } \\
\text { Instituto Provincial de Ciegos. } \\
\text { Centro Instructivo y Protector de Ciegos. }\end{array}$ \\
\hline Alicante: Alcoy. & Escuela Municipal de Ciegos. \\
\hline Almería: Almería & Colegio de Ciegos. \\
\hline Asturias: Gijón. & $\begin{array}{l}\text { Asociación "La Nueva Luz". } \\
\text { Escuela Municipal de Ciegos. }\end{array}$ \\
\hline Badajoz: Badajoz. & Escuela de Ciegos del Hospicio Provincial. \\
\hline Baleares: Palma de Mallorca. & Escuela Municipal de Ciegos. \\
\hline Barcelona: Barcelona. & $\begin{array}{l}\text { Escuela Municipal de Sordomudos y de Ciegos. } \\
\text { Instituto Educativo Catalán para Ciegos. } \\
\text { Colegio de Ciegos "La Purísima Concepción" de las } \\
\text { Hermanas Franciscanas. } \\
\text { Academia de Ciegos de la Casa Provincial de la Caridad. } \\
\text { Asociación "La Protección Mutua". } \\
\text { Asociación "Patronato de Cataluña para el Mejoramiento } \\
\text { Social del Ciego". } \\
\text { "Patronato de Cultura y Trabajo de los Ciegos de la } \\
\text { Provincia de Barcelona". } \\
\text { Montepío de Ciegos "La Unión Fraternal". } \\
\text { Biblioteca del Patronato de Cataluña. } \\
\text { Biblioteca del Instituto Educativo Catalán para Ciegos. }\end{array}$ \\
\hline Cádiz: Cádiz. & Colegio de Ciegos San Rafael. \\
\hline Castellón: Castellón. & $\begin{array}{l}\text { Sociedad de Ciegos "El Porvenir". } \\
\text { Escuela Provincial de Ciegos. }\end{array}$ \\
\hline Córdoba: Córdoba. & Colegio de Ciegos. \\
\hline Granada: Granada. & Centro Instructivo y Protector de Ciegos. \\
\hline Guipúzcoa: San Sebastián. & Colegio de Niñas Ciegas de San Rafael. \\
\hline Huesca: Huesca. & Colegio de Ciegos. \\
\hline La Coruña: La Coruña. & Escuela de Ciegos. \\
\hline La Coruña: Santiago de Compostela. & Colegio Regional de Sordomudos y de Ciegos. \\
\hline Madrid: Madrid. & $\begin{array}{l}\text { Colegio Nacional de Sordomudos y de Ciegos. } \\
\text { Escuela Municipal de Sordomudos y de Ciegos de la zona Sur. } \\
\text { Escuela Municipal de Sordomudos y de Ciegos de la zona Norte. } \\
\text { Colegio Santa Catalina de los Donados. } \\
\text { Centro Instructivo y Protector de Ciegos. } \\
\text { Asociación de Ciegos "Esperanza y Fe". } \\
\text { Biblioteca de la Escuela Municipal de Ciegos de la zona Sur. } \\
\text { Biblioteca Circulante del Centro Instructivo y }\end{array}$ \\
\hline
\end{tabular}


Régimen Jurídico de la Beneficencia y atención a los invidentes españoles en el siglo XX

\begin{tabular}{|l|l|}
\hline & Protector de Ciegos. \\
\hline Málaga: Málaga. & $\begin{array}{l}\text { Instituto Municipal de Ciegos. } \\
\text { Centro Instructivo y Protector de Ciegos. }\end{array}$ \\
\hline Pontevedra: Vigo. & $\begin{array}{l}\text { Escuela Municipal de Ciegos. } \\
\text { Asociación Instructiva y Protectora de Ciegos. }\end{array}$ \\
\hline Salamanca: Salamanca. & Escuela de Ciegos del Hospicio Provincial. \\
\hline Santander: Santander. & Sociedad de Ciegos "La Unión". \\
\hline Sevilla: Sevilla. & Escuela de Ciegos del Hospicio Provincial. \\
\hline Valencia: Valencia. & Instituto Valenciano de Ciegos. \\
& Asociación de Ciegos "El Porvenir". \\
\hline Vizcaya: Bilbao. & Sociedad Cultural y Protectora de los Ciegos de Vizcaya. \\
& Colegio de Sordomudos y de Ciegos (Deusto). \\
\hline Vizcaya: Portugalete. & Sociedad de Ciegos e Inválidos. \\
\hline Zaragoza: Zaragoza. & Instituto de Ciegos de las Hermanas Franciscanas. \\
& Escuela de Ciegos del Hospicio Provincial. \\
& Centro Instructivo y Protector de Ciegos. \\
\hline
\end{tabular}

En 1900, en toda España, sólo 136 ciegos estaban escolarizados en centros especiales, en 1919 son 545. El Colegio Nacional de Sordomudos y Ciegos de Madrid $^{79}{ }^{80}$, el centro mayor y más prestigioso, no superó la veintena de alumnos ciegos hasta la década de los setenta. Durante el sexenio revolucionario

79 Vide Alberto DAUDÉN TALLAVÍ, Los ciegos como grupo social y su relación con el Estado: 18001938, o.c., p. 172, donde reproduce el reconocimiento obtenido por parte de la imprenta del Colegio Nacional de Sordomudos y Ciegos, de 27 de noviembre de 1876:

«Dirección General de Instrucción Pública.

$1^{\underline{a}}$ enseñanza.

Excmo. Sr.:

La imprenta del Colegio Nacional de Sordo-mudos y de Ciegos establecida hace muchos años con el doble carácter de taller para el aprendizaje de los alumnos y de establecimiento tipográfico para el público por espacio de muchos años, dejó de ser un medio productivo, en 30 de junio de 1874. En esta fecha, la imperiosa necesidad de reducir el presupuesto general del Estado, obligó al Gobierno a rebajar los gastos de la mencionada imprenta siendo despedido el personal que en ella trabajaba, quedando sólo el Regente, puesto que los aprendices son alumnos de la casa.

La mencionada imprenta se había conquistado uno de los mejores lugares entre las de su clase; como lo atestiguan las obras salidas de sus prensas Cartas del Cardenal D. Francisco Jiménez de Cisneros, los [...] ilustres, la descripción Geológico-minera de las provincias de Albacete y Murcia y muchas otras; tanto que en la Exposición de Viena y en la Nacional de Madrid obtuvo dicha imprenta diferentes premios.

Ya se considere como taller del Colegio, ya como establecimiento tipográfico, bien merece que le dé el conveniente desarrollo para que cumpla con el objeto de su creación y se utilice el material que posee en fundiciones, prensas, máquina y multitud de objetos de mucho valor que no sirven porque no se emplean. 
superó los cincuenta alumnos, pero en 1900 sólo tenía 35 alumnos ciegos, alcanzando los 109 en 1935. La enseñanza en estos colegios era, además, muy irregular. Mientras que algunos colegios disponían de locales propios, otros daban clases en los locales de la Casa de la Caridad o del Hospicio de la ciudad, conviviendo ciegos, sordos, huérfanos, ancianos y enfermos. Otras escuelas, como la de Zaragoza, eran la empresa particular de antiguos alumnos de otros colegios que, al terminar su escolarización y volver a sus lugares de origen, consiguieron convencer a las autoridades locales para que abrieran un colegio especial. Todos ellos (a excepción del Nacional de Madrid, y del de Santa Catalina) dependían de subvenciones locales, siempre precarias, lo que explica que algunos de ellos, como el de Burgos, aparezcan y desaparezcan de las estadísticas, mientas que otros desaparecen definitivamente. Además, debido a la carestía del material especial de enseñanza (libros en Braille, mapas en relieve, etc.), muchos de ellos carecían de lo indispensable.

Lo que sí ofrecían casi todas las escuelas era enseñanza musical. Un prejuicio o "teoría" de la época defendía que, por medio de una suerte de compensación sensorial, los ciegos eran extraordinariamente hábiles para la música. Con la enseñanza musical se intentaba compensar la desventaja que los ciegos tenían en los trabajos manuales. Por otro lado, la enseñanza musical era mucha más barata que la enseñanza de un oficio manual. Aquel prejuicio era tan arraigado que, a pesar de las protestas de profesores de los colegios especiales contra la idea de la aptitud natural del ciego para la música, la enseñanza musical, a falta de otras opciones más baratas, siguió siendo la enseñanza profesional preferente de los colegios.

\footnotetext{
El Negociado cree que es posible devolver a la imprenta de sordomudos su antiguo esplendor a muy poca cosa. [...]», y además destaca: «Al contrario que los sordomudos, que podían encontrar colocación externa, los ciegos que trabajaban en talleres protegidos necesitaban siempre alguna subvención para compensar sus salarios», y cuando faltaron las subvenciones los talleres cerraron.

80 Vide Roberto GARVIA SOTO, La organización nacional de ciegos. Un estudio institucional, Centro de Estudios Avanzados en Ciencias Sociales, Madrid, 1993, p. 47, nota 32: «Las subvenciones provenían de la Asociación Matritense que, a su vez, recibía la mayor parte de sus ingresos a través de un canon sobre los establecimientos de juego. El juego era ilegal, pero abiertamente tolerado como fuente de re cursos para atender los asilos y otros establecimientos de beneficencia. De hecho, los ingresos que obtenía la Asociación Matritense de los impuestos sobre el juego eran públicos, y su presidente, García Molinas, no deseaba otra cosa que el juego se reglamentara de forma definitiva. La tolerancia con el juego era frecuentemente objeto de debate público, pero ni se reglamentó ni se persiguió, con lo que surgían en ocasiones pequeños escándalos políticos y acusaciones de lucro partidista, que solían terminar en campañas de persecución contra el juego, para volver a tolerarlo cuando las aguas volvían a su cauce normal. [...]».
} 
En resumen, en los colegios especiales, los niños ciegos no aprendían más que a hacer mejor lo que venían haciendo los ciegos trovadores o los ciegos agremiados de Madrid, Zaragoza y otras muchas ciudades: tocar un instrumento y pedir limosna. Pero con una importante diferencia. Como consecuencia imprevista de la política de escolarización de la Matritense, los colegios especiales crearon una élite dotada del lenguaje adecuado para reclamar con voz propia, y al margen de sus empresarios institucionales (médicos, profesores, sociólogos) una mejora de la situación social de los ciegos ${ }^{81} 82$.

\section{La primera organización legal de ciegos en España}

En 1882 apareció en Madrid la primera organización legal de ciegos después de la desarticulación de la Hermandad "Esperanza y Fe". Era una organización de mendigos que tenía como objetivo el socorro para los casos de enfermedad y defunción. Pocos años más tarde, en 1894, antiguos alumnos del Colegio Nacional crearon el Centro Instructivo y Protector de Ciegos, también en Madrid. El centro era una sociedad de socorro mutuo y de resistencia contra las campañas de mendicidad. A diferencia de "Esperanza y Fe", el centro tenía una estrategia más elaborada, que consistía no tanto en reaccionar contra las campañas de represión de la mendicidad, como en anticiparse a ellas. Para ello intentaba cooptar a los ciegos más ilustres, a profesores del Colegio Nacional y a miembros de la clase política. Ambas organizaciones contaban con un periódico en Braille, El Monitor, que, aun no siendo órgano específico de ninguna de ellas, expresaba las opiniones de ambas.

\footnotetext{
${ }^{81}$ Ibídem, pp. 30-36.

${ }^{82}$ Vide. M. GRANELL y FORCADELL, "Ventajas de la relación directa de los ciegos con los videntes", Conferencia pronunciada en la Sociedad "El Porvenir" de Valencia, Imprenta del Colegio Nacional de Sordomudos y Ciegos, Madrid, 1914, pp. 9-26; Alberto DAUDEN TALLAVÍ, Los ciegos como grupo social y su relación con el Estado: 1800-1938, o.c., p. 56: «En el año 1894, los beneméritos ciegos Nicasio del Hierro, Antonio Ortega, Mariano Castellón y Juan Antonio Sánchez Andreu, de Madrid, pensaron en la creación de un centro para ciegos, donde los compañeros en desgracia pudieran cambiar impresiones sobre aquello que más les conviniera. El 5 de octubre de ese año, se funda el Centro Instructivo y Protector de Ciegos.

Esta institución no sólo se ocupaba de educar e instruir a los niños ciegos, sino que les protegía también. Las aspiraciones de dicho centro eran entre otras: constituir, fomentar y buscar toda clase de elementos que conduzcan al bien particular o colectivo de los individuos ciegos; establecer clases de enseñanza especial; satisfacer las necesidades de los ciegos, creando secciones, cooperativas, etc.».
} 
En las páginas de El Monitor se insistía en la capacidad del ciego para desempeñar un trabajo manual, se hacían llamamientos a la unidad de los ciegos de toda España y se inició una campaña contra el Colegio Nacional, al que se calificaba como "fábrica de mendigos". Esta campaña tuvo eco en algunos profesores del Colegio Nacional, quienes no escondían su frustración al ver a antiguos alumnos mendigar en las calles, haciendo inútiles todos sus esfuerzos docentes.

La situación queda expuesta con mucha claridad en la carta dirigida a S.M. la Reina por parte de la Municipalidad de Barcelona el 1 de abril de $1893^{83}$.

${ }^{83}$ Ibídem, pp. 177-179:

«Señora,

El Ayuntamiento de Barcelona con la mayor veneración se acerca al trono de S.M., y respetuosamente expone: Que respondiendo V.M. con maternal explicitud a los sentimientos de piedad que abriga su corazón, en favor de los infelices que privados de sus más preciosos sentidos carecen de los recursos indispensables a la vida común, se ha dignado disponer con distintas leyes y Reales Ordenas la creación de varios establecimientos para asilo y amparo de los ciegos y sordomudos que divagan por todo el Reyno. Cercano pues, Señora, el día en que Vuestro Gobierno, oída la Junta General de Beneficencia, señalará los puntos donde hayan de situarse dichos Establecimientos, cree cumplir esta Corporación con otro de sus más sagrados deberes, encareciendo a V.M. la necesidad y conveniencia general de que sea erigido uno de cada clase en la población que representa.

Animadas en todos tiempos las Municipalidades de Barcelona de los más piadosos sentimientos, y movidas las de los años 1816 y 1820 por tan generosos impulsos, acogieron benévolamente y alentaron el proyecto de proporcionar alguna enseñanza a los Ciegos y Sordomudos, abriendo bajo sus auspicios y protección dos escuelas públicas, cuyos Establecimientos destinados exclusivamente a la instrucción moral e intelectual de aquellos infelices, han sido costeados siempre y se sostienen ahora de los fondos del Común.

Estos sacrificios, Señora, no bastan por más que sea doloroso el consignarlo. Careciendo esta Capital de una Casa en la que puedan recogerse los Ciegos y Sordo-mudos, suministrándoseles los auxilios necesarios a la humana existencia, llega a centenares el número de los que, acosados por la miseria, recorren sus plazas y paseos contristando el ánimo público con sus lastimeros gemidos, único recurso que en su triste situación poseen. Pero este cuadro desgarrador es tanto más aflictivo para este Ayuntamiento en cuanto se ve privado de ocurrir a aquellas necesidades, en primer lugar porque siendo declarados generales aquellos Establecimientos, no puede sostenerlos una Municipalidad; y en segundo, porque sus sostenimiento excedería a los recursos de la de Barcelona.

En tal conflicto, Señora, no puede menos esta Corporación de exponer a V.M. las razones que abonan la conveniencia de crearlos en esta Ciudad. Aumentando considerablemente el número de sus moradores, lo que la constituye la segunda Capital de España en este concepto, se recogen en su recinto, no ya los naturales de la misma y su Provincial sino también los de las limítrofes, resultando de esto que aquellos desventurados viven en las mayores privaciones, mendigando su sustento y colocados en la pendiente del vicio, de la abyección y hasta del crimen; por manera que 
En parte para remediar esta situación ${ }^{84}$, y también para elaborar un curriculum uniforme en las escuelas especiales, el Comisario Regio del Colegio Nacional de Sordomudos y Ciegos convocó una Asamblea Nacional para el Mejoramiento de la Suerte de los Ciegos y los Sordomudos. La Asamblea se celebró en Madrid en diciembre de 1906. Asistieron profesores de colegios es-

aunque se mandase salir de la Provincia a los que no son naturales de ella, siempre los habría en gran número, particularmente ciegos, en razón a predisponer a esta enfermedad ciertas industrias de las que se ejercen en esta Capital; todo lo que justifica más y más el acierto con que se procedería a crear en la misma dichos Establecimientos, pues de lo contrario se obligaría a aquellos desgraciados a buscar el socorro público lejos de sus familias, cuando estos seres, por su triste condición necesitan con preferencia a otros algunos, el consuelo de estas afecciones.

Y como la experiencia acredita que en los climas meridionales son más comunes las enfermedades de la vista, y que fácilmente degeneran en ceguera absoluta, fenómeno que desgraciadamente se observa no sólo en esta Capital sino en todas las provincias cercanas que se encuentran en la propia situación topográfica: concurre esta poderosa razón a demostrar, no ya la conveniencia, sino la necesidad de que se instale en Barcelona un establecimiento destinado a recoger a las víctimas de tan lastimosa dolencia.

De otra parte, en esta población esencialmente industrial, además de la instrucción moral, civil y religiosa, puede enseñarse a los Ciegos y Sordo-mudos ciertas artes manuales, no contrayéndose solamente a la música en cuanto a los primeros, con cuyo ejercicio les sería [...] atender por sí mismos su subsistencia, pasando a ser miembros útiles a la Sociedad en vez de gravarla con su inacción; ya sea porque saliendo instruidos del Establecimiento encontrarían más fácilmente una colocación proporcionada a sus conocimientos, o bien porque aun permaneciendo en él pudiera darse, procurándole así recursos, pronta salida a los productos elaborados, aligerando al Estado en la subvención que les asigne.

La situación topográfica de Barcelona arguye también Señora, en favor de la providencia que esta Corporación se atreve a reclamar de la munificencia de V.M. Centro de cuatro Provincias pobladísimas, y casi centro de Aragón, Valencia e Islas Baleares, que figuran por algunos millones de habitantes en el censo de población, la traslación de los individuos que debiesen recogerse en las referidas Casas sería más expedita para la Administración, menos molesta para los recogidos, y menos dispendiosa para los pueblos, conciliándose de esta suerte todos los grandes intereses que V.M. está llamada a vigilar.

Confía pues, sobradamente este Cuerpo municipal en la ilimitada benevolencia de V.M. para no esperar que hallarán cabida en su augusto corazón las reflexiones que inducen al mismo a distraerla de sus altas atenciones y con esta esperanza

A los R [...] P.P de V.M. reverentemente suplica: se digne disponer que de las varias Casas de Ciegos y de Sordo-mudos que deben existir en todo el Reyno, se erija una de cada clase en esta Capital. Gracia que no duda alcanzar de V.M. por cuya vida y prosperidad de la Nación ruega fervorosamente al Todo Poderoso.

Barcelona, 1ํㅡㄹ Abril de 1893»

${ }^{84}$ Vide E. CANORA y MOLERO, La luz del alma, estudio sociológico moral sobre el ciego, Imprenta Nacional de Sordomudos y Ciegos, Madrid, 1906, pp. 9-11. 
peciales de toda la península, médicos, pedagogos y representantes del Centro Instructivo y Protector de Ciegos. Estos últimos no consiguieron que el resto de los asambleístas reconocieran el derecho de los ciegos a mendigar sin ser molestados, pero, al menos, entre las conclusiones de la Asamblea se recomendaba "que debe prohibirse la reclusión de los ciegos en los asilos ordinarios de mendicidad", al tanto que se invitaba a los colegios especiales a introducir los talleres de aprendizaje profesional.

La Asamblea también recomendó la creación de un Patronato que estudiara las medidas oportunas para remediar la situación de los ciegos, los sordomudos y los anormales ${ }^{85}$.

La creación del patronato y sus reformas generó un modelo caduco que sería modificado sustancialmente a lo largo del siglo XX.

85 Vide Roberto GARVIA SOTO, La organización nacional de ciegos. Un estudio institucional, o.c., pp. $40-42$. 